Review

\title{
A classification scheme for interfacial mass transfer and the kinetics of aroma release
}

\author{
Martijn Weterings $^{\mathrm{a}, \mathrm{b}}$, Igor Bodnár ${ }^{\mathrm{c}}$, Remko M. Boom ${ }^{\mathrm{b}}$, Michael Beyrer ${ }^{\mathrm{a}, *}$ \\ a Institute of Life Technologies, University of Applied Sciences and Arts Western Switzerland, Route du Rawyl 47, 1950, Sion, Switzerland \\ ${ }^{\mathrm{b}}$ Food Process Engineering Group, Wageningen University and Research Centre, PO Box 18, 6700 AA, Wageningen, the Netherlands \\ ${ }^{\mathrm{c}}$ Firmenich S.A, Rue de la Bergère 7, 1217, Meyrin 2, Geneva, Switzerland
}

\section{A R T I C L E I N F O}

\section{Keywords:}

food processing

Food modelling

Aroma classification

Aroma release dynamics

Flavor release

Air water mass transfer

Interfacial mass transfer

\begin{abstract}
A B S T R A C T
Background: The study of aroma release has gained popularity in food science. Nowadays, experiments become increasingly more complex. However, an application of theories on mass transfer, which may help to better explain the results, is lagging behind on these developments.

Scope and approach: The goal of this review is to get together, in a concise way, the state of the art on fundamental knowledge of mass transfer in aroma release plus creating an extension of theory with a comprehensible classification that is useful for food scientists. The existing mathematical model is simplified and points that have received little attention are identified.

Key findings and conclusions: An overview of experimental studies that focus on the influence of viscosity on aroma release show that there is heterogeneity in results and no consensus exists on the influence of viscosity. Such heterogeneity may be better understood with the effects of mass transfer. These effects are summarized by describing three implications based on non-proportional relationships between the partition coefficient and (A) the overall mass transfer coefficient, (B) the depletion and saturation time-scales, and (C) the peak value of the aroma concentration in the head space. A classification scheme is made to enable food scientists and technologists to apply the complex description in shorter and simpler terms that can be communicated and compared more easily. The scheme depends on a classification in two dimensions based on a thermodynamic factor, the partition coefficient, and a kinetic factor which divides aroma's and experiments into four different classes.
\end{abstract}

\section{Introduction}

\subsection{Background}

Two developments in the recent past have driven an increased activity in the study of aroma release. First, the possibility to study aroma release with higher precision came with the development of powerful online aroma analysis tools (Lindinger, Hansel, \& Jordan, 1998; Linforth \& Taylor, 1996). Second, the increasing demands of product reformulations to provide more sustainable and healthy food products (Buttriss, 2013), which requires more insights in the complex relations of aroma release with other food components and food processing, to ensure the same aroma intensity and profile after product reformulation. Aroma release has now become a multi-disciplinary field of research with complex studies (Fisk, 2015; Guichard, 2000; Roberts \& Taylor, 2000).

Among the complex and rich disciplines, mostly equilibrium states are observed, or non-equilibrium states are compared with simplified empirical models only. Most reviews, book chapters and thesis-work are placing a focus on aroma matrix interactions, experimental methods or specific food products:

- Aroma matrix interactions: general interactions (Guichard, 2015; Hollowood, 2002; Rusu, 2006; van Ruth \& Roozen, 2010; Voilley \& Souchon, 2006), carbohydrates (Conde-Petit, Escher, \& Nuessli, 2006; Delarue \& Giampaoli, 2006; Naknean \& Meenune, 2010; Tietz, 2007), lipids (Ollivon, Voilley, Etiévant, \& others, 2006), proteins (Dolu, 2013; Tromelin, Andriot, \& Guichard, 2006), liquids (Boelrijk et al., 2006), thickened foods (Lubbers \& Etiévant, 2006), emulsions (de Roos, 2003; Dumont, 2006; McNulty, 1987), dispersions (Pearson, 2005), wine (Muñoz-González, Rodríguez-Bencomo, Moreno-Arribas, \& Pozo-Bayón, 2011; Villamor \& Ross, 2013), yoghurt (Saint-Eve, 2006), dairy (Gierczynski, Guichard, \& Laboure, 2011).

\footnotetext{
* Corresponding author.

E-mail address: michael.beyrer@hevs.ch (M. Beyrer).
} 
- Experiments and methods: on line analysis techniques (Taylor \& Linforth, 2010), in vitro analysis techniques of oral consumption (Déléris, Saint-Eve, Kauffmann, Feron, \& Souchon, 2015; Morell, Hernando, \& Fiszman, 2014).

- Specific food or processing systems: thermal processing and effects of encapsulation (de Roos, 2006b), oral release during consumption (Harrison, Cleary, Eyres, D.Sinnott, \& Lundin, 2014; Linforth \& Taylor, 2006; Taylor, 2002), sensory and perception (Nahon, 1999; Weel, 2004), flavor reformulation and optimization (Raffo, 2012; Yang, 2012).

However, the aroma release from food products is by definition not in an equilibrium state. Yet, only in a much smaller body of research (reviews, book chapters and thesis-work) the focus has been on mass transport and the kinetics of aroma release:

- Thermodynamics and mass transport mechanisms: modelling release (de Roos, 2006a; Linforth, 2010), descriptions of mass transport (Atlan, 2007; Bortnowska, 2010; Cayot, Dury-Brun, Karbowiak, Savary, \& Voilley, 2008), theoretic treatment of drying processes (Coumans, Kerkhof, \& Bruin, 1994).

This means that a lot of scientific works explain their findings to a limited extend. This low attention to kinetics may reduce the valorisation of the wide range of research that is difficult to connect to the dynamics and high variability in real life situations. The principles describing the aroma release as a dynamic state may help to better explain, understand, and quantify aroma release in various circumstances.

\subsection{Scope and structure of this report}

This report consist of four parts (sections 2 to 5). In section 2 we describe the mathematical model that is commonly used in descriptions of aroma release from liquid to headspace, and describes the mass transfer based on fundamental principles. In an appendix we add a new description of an alternative derivation of the mathematical model by applying a simpler method and by introducing simplifications with dimensionless numbers. This model, which is the main scope of this paper, provides a great clarity and understanding of basic aroma release processes, whose applications and merits we discuss in the further sections. It is out of our scope to present an in-depth description of a full model of more complex systems.

In Section 3 we show that the mathematical model can be summarized, by three main implications with respect to the effect of the partition coefficient on the kinetics of aroma release. These implications have been described before in the literature. However, these implications and the mathematical formulation are not well assimilated in the paradigms that are used in the study and description of aroma release. This is illustrated with an overview of heterogeneous results in studies on the effect of viscosity on aroma release leading to a lack of consensus.

In section 4 we briefly look beyond the scope of the mathematical model, and describe the theoretic and experimental engineering models of mass transfer across an interface. Our goal is not to provide a detailed explanation of these tools. Yet, we wish to make clear how these models and correlations have currently been applied and show that this area has space for promising developments in the future. Chemical engineers have described and studied many situations with this formalism, but this knowledge has not yet been linked entirely with research on aroma release.

In Section 5 we provide an intuitive and simple description to a classification scheme that follows from the previous sections. The classification system contains simple but correct expressions that can be used in place of the complex mathematical structure in the first, second and third part. The classification is based on a chemical factor based on

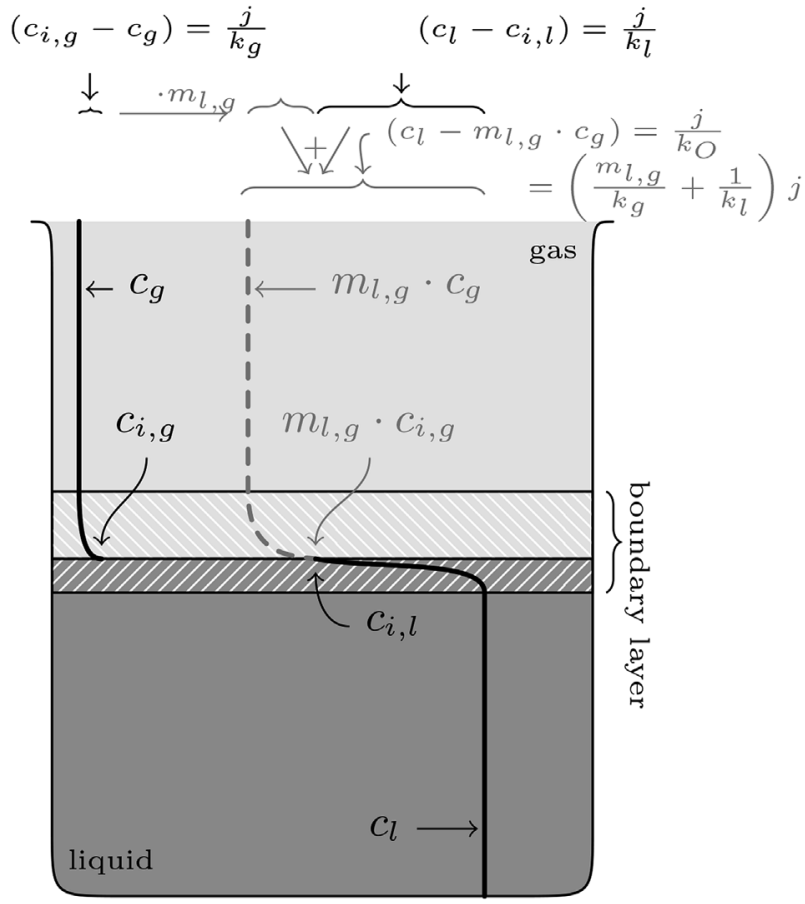

Fig. 1. Schematic drawing of the aroma concentration profile in a model with two, individually well mixed, phases. The grey dashed line depicts an intuitive view of the algebra for the derivation of equation (6). The overall mass transfer, using the concentration difference $\left(c_{l}-m_{l, g} \cdot c_{g}\right)$, can be expressed by multiplying the concentration difference $\left(c_{i, g}-c_{g}\right)$ with $m_{l, g}$ and adding to the difference $\left(c_{l}-c_{i, l}\right)$.

the product/air or liquid/gas partition coefficient as well as a kinetic factor based on the air flow condition or stripping factor. The stripping factor is an addition in classification that is often underestimated and has not been used before. Also, kinetic factor is able to express the nonproportional relation between the effective aroma release and the partition coefficient, which is relevant in all cases that deal with dynamic aroma release processes. In those cases with less well defined air flow conditions, a stripping flow, which can be quantified very well in controlled experiments, can be interpreted in qualitative terms.

\section{Aroma release from liquid to headspace}

The situation of aroma release that we focus on is shown schematically in Fig. 1. Two phases, that are individually well mixed in the bulk, are in contact with each other, and the system is in thermodynamic dis-equilibrium with an unequal potential for the aroma concentration between the two phases.

The assumption of two individually well mixed phases, allows to assume the aroma concentration to be homogeneously distributed in the bulk of both phases. The largest aroma concentration gradient exists in a small layer at the interface, which dominates the resistance to mass transfer. Variations on this theme exist in which the phases are not well mixed, such as in solid phases, or unstirred highly viscous systems. In those cases the fundamentals of mass transfer are mostly the same yet the solution requires to compute diffusion throughout the entire system rather than a thin layer and simplified expressions become more difficult to obtain.

Other assumptions that are often made is that the mass transport is described, simplified, by the aroma concentrations and Fickian diffusion. In the case of mass transfer with multiple components (for example water vapour during a drying process or ethanol transport in wine samples) this assumption does not hold. There is also little consideration of convection mechanisms beyond forced convection, such as 
temperature gradients. These cases of non-forced convection may not always occur, or be of mayor importance, yet there are only few examples that describe these effects in aroma release (an example is Tsachaki, Linforth, and Taylor (2009) who describe a Marangoni effect in wine).

In Fig. 1 an aroma concentration gradient is drawn and several expressions for certain locations in the concentration gradient are placed. In the next section we discuss in more detail these concentrations, which are relevant for the expression of the driving force of mass transfer. First we look at the general formula that others have used to describe the solution for the headspace aroma concentration, $c_{g}(t)$, as a function of time.

\subsection{Mathematical model}

Harrison and Hills (Harrison, Hills, Bakker, \& Clothier, 1997; Harrison \& Hills, 1997a, 1997b; Hills \& Harrison, 1995) derived solutions to the equations belonging to the specific case of aroma release from one phase to another. Their main results give the time-concentration profile of the aroma in the headspace above a food product, $c_{g}(t)$, as a linear combination of two exponential functions in time

$c_{g}(t) \propto e^{-t / \tau_{d}}-e^{-t / \tau_{r}}$

where $\tau_{d}$ and $\tau_{r}$ are timescales for the change in the exponential terms, we will see later that these depend on the properties of the aroma, food matrix and the geometry of the system. The subscripts $d$ and $r$ are chosen because these timescales relate to a dilution phase and a release phase. In section 5 we explain the timescales in more intuitive terms.

It is often mentioned that Harrison and Hills apply different theoretical engineering models that we describe further on in this report, but this is not effectively the case. In the case of release from liquids the different models do not change the form of equation (1). The equations are similar each time with only an adaptation in the mass transfer coefficient. In the case of release from solids the equations are adapted (Juteau-Vigier et al., 2007), but variations in the mass transfer coefficients are still not part of the mathematical model.

Some slight modifications for more complicated models have been made. Models have gradually increased in complexity from simple enclosed systems (Hills \& Harrison, 1995) to systems with an additional air flow (Harrison \& Hills, 1997a), emulsions (Harrison et al., 1997) or aroma binding polymer solutions (Harrison \& Hills, 1997b), to systems with an additional liquid phase (Normand, Avison, \& A, 2004) or eight multiple components (Déléris, Saint-Eve, Saglio, Souchon, \& Trelea, 2016) to mimic interactions with saliva and other compartments in the oral cavity. All those models can be described as compartment models, which are also widely used in pharmacological sciences, and the mathematical description (Godfrey, 1983) is widely developed. Modifications beyond these compartment models, which do not require the simplification of homogeneous distribution in the bulk, make use of partial differential equations (Atlan, 2007; Jousse et al., 2002) or integrate the mass transfer into a multiphysics model (Harrison et al., 2014). More general descriptions of mass transfer, with Maxwell-Stefan equations (not requiring the simplification of Fickian diffusion), have been applied to the problem of aroma release by chemical engineers (Coumans et al., 1994).

We provide a derivation to the equations of Harrison and Hills (1997a) in order to apply some simplifications. While Harrison and Hills use a laplace transformation to solve the equations, we simply solve the equations by supposing a combination of exponential functions. This is a valid method for any set of coupled linear ordinary differential equations with constant coefficients. The full solution is

$$
\begin{aligned}
& C_{g}(t)=\frac{c_{g}(t)}{c_{l}(0)}=\frac{e^{-\left(m_{a}-\sqrt{m_{a}^{2}-4 \xi \xi \beta}\right) \cdot \frac{t}{2 \tau_{g}}}-e^{-\left(m_{a}+\sqrt{m_{a}^{2}-4 \xi \beta}\right) \cdot \frac{t}{2 \tau_{g}}}}{\sqrt{m_{a}^{2}-4 \xi \xi \beta}} \\
& \text { and } m_{a}=\beta+m_{l, g}+\xi
\end{aligned}
$$

in which we use the following dimensionless numbers and time scales: the gas-liquid volume ratio $\beta=\frac{V_{g}}{V_{l}}$, the stripping transport coefficient ratio $\xi=\frac{\Phi}{k_{O} A}$, the liquid/gas partitioning coefficient, $m_{l, g}=\frac{c_{l}^{e q}}{c_{g}^{e q}}$, a term $m_{a}$ for the expression $m+\beta+\xi$, which we define as the dynamic partition parameter and use to simplify the equations, and a time scale based on the ratio of mass transport across the interface and the storage capacity of the gas phase volume $\tau_{g}=\frac{V g}{k_{O} A}$. In addition we use the gas head space volume $V_{g}$, the liquid food sample volume $V_{l}$, the stripping flow $\Phi$, the overall mass transfer coefficient $k_{O}$, the interface area $A$ and the time $t$. The term $C_{g}(t)$ is the head space aroma concentration $c_{g}(t)$ made dimensionless by division with the initial aroma concentration in the liquid $c_{l}(0)$.

Except for the modification to parameters (using the dimensionless parameters and timescales $m_{l, g}, \xi, \tau_{g}$ and $\beta$ ) this form is identical to the equations of Harrison and Hills (1997a). Simplifications for special cases, which we also derive in the appendix, are:

- In the case that the gas flow to and from the headspace is small $4 \xi \beta \ll\left(\beta+m_{l, g}+\xi\right)^{2}$ we get:

$C_{g}(t) \simeq \frac{e^{-\left(\frac{\xi \beta}{\beta+m_{l, g}}\right) \frac{t}{2 \tau g}}-e^{-\left(\beta+m_{l, g}\right) \frac{t}{2 \tau g}}}{\beta+m_{l, g}}$

- If in addition $m_{l, g}$ is small as well (compounds with high vapour pressure and/or low solubility) then:

$\lim _{m l, g \rightarrow 0} C_{g}(t)=\frac{e^{-\xi \frac{t}{\tau_{g}}}-e^{-\beta \frac{t}{\tau_{g}}}}{\beta}$

- In the case that the gas flow is high $\xi \gg \beta$ then equation (2) becomes approximately:

$C_{g}(t) \simeq \frac{e^{-\left(\frac{2 \xi \beta}{m+\xi}\right) \frac{t}{\tau_{g}}}-e^{-(\xi+m l, g) \frac{t}{\tau g}}}{m_{l, g}+\xi}$

\subsection{The overall mass transfer rate}

The overall mass transfer per unit area, from a liquid to a gas phase or vice versa, $j\left[\mathrm{~mol} \mathrm{~m}^{-2} \mathrm{~s}^{-1}\right]$, is commonly related to the difference in concentration of bulk liquid and bulk gas phase, $\left(c_{l}-m \cdot c_{g}\right)$ with $m_{l, g}=c_{l}^{e q} / c_{g}^{e q}$ the partition coefficient. The proportionality between the mass transfer and the overall concentration difference is given by the overall mass transfer coefficient, $k_{O}\left[\mathrm{~mol} \mathrm{~m} \mathrm{~s}^{-1}\right]$, which can be determined by taking the sum of the dominating resistances to mass transfer, the liquid and gas film layers close to the interface, $\frac{1}{k_{O}}=\frac{1}{k_{l}}+\frac{m_{l, g}}{k_{g}}$ (Lewis \& Whitman, 1924):

$j=k_{O}\left(c_{l}-m_{l, g} c_{g}\right)=\left(\frac{1}{k_{l}}+\frac{m_{l, g}}{k_{g}}\right)^{-1}\left(c_{l}-m_{l, g} c_{g}\right)$

\section{Implications of the mathematical model}

\subsection{Non-proportional dependencies with the partition coefficient}

equations (2) and (6) comprise non-proportional dependencies of the liquid/gas partition coefficient $m_{l, g}$, which can be resolved into three different terms:

- $\frac{1}{\mathbf{k}_{\mathbf{O}}}=\frac{1}{\mathbf{k}_{\mathbf{l}}}+\frac{\mathrm{m}_{\mathrm{l}, \mathrm{g}}}{\mathbf{k}_{\mathrm{g}}}$ resulting in a different description of the overall mass transfer coefficient depending on the relation between the mass transfer Biot number, $\frac{k_{g}}{k_{l}}$, and the partion coefficient, $m_{l, g}$, 
$k_{O}=\left(\frac{1}{k_{l}}+\frac{m_{l, g}}{k_{g}}\right)^{-1} \sim\left\{\begin{array}{cl}\frac{k_{g}}{m_{l, g}}, & \text { if } \frac{k_{g}}{k_{l}}<m_{l, g} \\ k_{l}, & \text { if } \frac{k_{g}}{k_{l}}>m_{l, g}\end{array}\right.$

The implication is an overall mass transfer coefficient that is dominated by the mass transfer in the gas phase if the liquid/gas partition coefficient is large, and dominated by the mass transfer in the liquid phase if the liquid/gas partition coefficient is small. The mass transfer varies proportionally with the inverse of the liquid/gas partition coefficient if the liquid/gas partition coefficient is small, but remains constant as function of the partition coefficient if the liquid/gas partition coefficient is high.

- $\left(\mathbf{c}_{1}-\mathbf{m}_{1, \mathrm{~g}} \mathbf{c}_{\mathrm{g}}\right)$ resulting in a different description of the rate of change of the driving force depending on the relation between the gas-liquid phase ratio, $\beta$, and the partion coefficient, $m_{l, g}$,

$\frac{\partial\left(c_{l}-m_{l, g} c_{g}\right)}{\partial t} \sim\left\{\begin{array}{cl}\frac{\partial c_{l}}{\partial t}, & \text { if } \beta>m_{l, g} \\ \frac{m_{l, g} \partial c_{g}}{\partial t}, & \text { if } \beta<m_{l, g}\end{array}\right.$

The implication is a rate of change in the driving force that is dominated by a depletion of the liquid phase if the liquid/gas partition coefficient is small, and a rate of change in the driving force that is dominated by a saturation of the gas phase if the liquid/gas partition coefficient is high.

- $\mathbf{m}_{\mathbf{a}}=\mathbf{m}_{\mathbf{l , g}}+\beta+\xi$ resulting in a different description of the gas-liquid concentration ratio depending on the relation between the stripping transport coefficient ratio, $\xi=\frac{\Phi}{k_{O} A}$, and the partion coefficient, $m_{l, g}$,

$m_{a}=m_{l, g}+\beta+\xi \sim\left\{\begin{array}{cl}\xi+\beta, & \text { if } \xi>m_{l, g} \\ m_{l, g}+\beta, & \text { if } \xi<m_{l, g}\end{array}\right.$

The implication is a gas-liquid concentration ratio that is dominated by the stripping transport coefficient ratio if the liquid/gas partition coefficient is small, and a gas-liquid concentration ratio that is dominated by the partition coefficient if the liquid/gas partition coefficient is high.

The implications of these three dependencies are treated differently in the literature on aroma release. The effects are not trivial and not always taken into consideration. We will describe next the implications more precisely and argue why they should be considered more often.

\subsection{Implication 1: the overall mass transport coefficient $\frac{1}{k_{O}}=\frac{1}{k_{l}}+\frac{m_{l, g}}{k_{g}}$}

In Fig. 1 we have drawn a sketch for derivation of the overall mass transfer rate, $k_{O}$, including the dependency on the partition coefficient, $m_{l, g}$, and the mass transfer coefficient in the gas, $k_{g}$, and liquid, $k_{l}$. This leads to a difference between aroma compounds of high and low $m_{l, g}$, relative to the ratio $\frac{k_{g}}{k_{l}}$. Changes in the system that have an effect on the liquid transfer coefficient or the partition coefficient may have different effects for different types of aroma compounds and systems.

Some researchers argue for neglecting the mass transfer in the gas layer because the concentration difference between the bulk and the interface in the gas phase $\left(c_{i, g}-c_{g}\right)$ can be neglected (de Roos, 2003; van Ruth \& Roozen, 2010). However, the mass transfer in the gas layer resistance may still be important depending on the value of $m_{l, g}$. If the overall mass transfer coefficient, $k_{O}$, is not made dependent on the partition coefficient, $m_{l, g}$, and if it is assumed that the transport coefficient does not differ much between the different aroma compounds because there is only little variation among different aroma molecules in $k_{l}$ and $k_{g}$ mass diffusion coefficients (Bortnowska, 2010; de Roos, 2006b), then the variation in the overall mass transfer coefficient is wrongly underestimated.
The liquid/gas partition coefficient spans a range of eight orders, from $10^{-1}$ to $10^{7}$, for aroma molecules in water at $25^{\circ} \mathrm{C}$ (US EPA, 2012), which has a great influence on the term $\frac{m_{l, g}}{k_{g}}$. If $m_{l, g}>\frac{k_{g}}{k_{l}}$ then the gas film dominates the overall mass transport coefficient and the resistance increases roughly linearly with increasing $m_{l, g}$. If $m_{l, g}<k_{g} / k_{l}$ then the liquid film dominates the overall mass transport coefficient and the resistance remains roughly constant with variations in $m_{l, g}$. A typical value for $k_{g} / k_{l}$ is around $10^{2}$ if the liquid is water, and more viscous systems will have higher values. The variation in the overall mass transfer coefficient is thus very large, depending linearly on the partition coefficient $m_{l, g}$ with a change around $k_{g} / k_{l}$ from linear variation to constant.

\subsection{Implication 2: rate of change in driving force $\left(c_{l}-m \cdot c_{g}\right)$}

There are two ways in which the driving force, the concentration gradient $\left(c_{l}-m_{l, g} \cdot c_{g}\right)$, changes in a release process of aroma from a liquid sample to the head space: (1) the gas concentration $c_{g}$ increases (saturation of the head space) and (2) the liquid concentration $c_{l}$ decreases (depletion of the sample). The one effect may be more important than the other, which depends on the volumes of the liquid and the gas, as well as the partition coefficient.

We have the initial rates of concentration change (see Appendix equations (18) and (19) starting with the initial situation in which $c_{g}=0$ ) of

$\frac{\partial c_{l}}{\partial t}=-\tau_{g} \beta c_{l} \quad$ and $\quad \frac{\partial c_{g}}{\partial t}=\tau_{g} c_{l}$

such that we have the relative driving force change:

$\frac{\partial\left(c_{l}-m_{l, g} \cdot c_{g}\right)}{\partial t}=-\left(m_{l, g}+\beta\right) \tau_{g}$

This leads to a difference between aroma compounds of high and low $m_{l, g}$ relative to gas-liquid phase ratio. For $m_{l, g}>\beta$ the gas/liquid volume ratio is small and the liquid/gas partition coefficient is high, which results in the gas concentration change being more relevant and a stronger influence of the partition coefficient and the gas volume on the relative change in the concentration difference. For $m_{l, g}<\beta$ the gas/liquid volume ratio is high and the liquid/gas partition coefficient is low, which results in the liquid concentration change being more relevant, a stronger influence of the liquid volume and little influence of the partition coefficient on the relative change in the concentration difference.

\subsection{Implication 3: dynamic partition parameter $m_{a}=m_{l, g}+\frac{\Phi}{A K_{O}}$}

In a closed system without stripping flow, when the aroma concentrations in the headspace and the liquid reach an equilibrium, $c_{l}=m_{l, g} \cdot c_{g}$, then the mass transport between the two phases decreases to zero and a steady state value for the aroma concentrations is reached. If the system is not closed and a flow is considered that strips the headspace then this value will never be reached. The seemingly steady state aroma concentration in the headspace will be lower. This value is determined by the mass transport between liquid phase and gas phase across the interface equalling the mass transport away from the gas phase due to the stripping flow. In this case the concentration change of the gas phase reaches zero and a peak value is reached, which may be an apparent steady state value if the system does not change much further.

Using $\Phi\left[\mathrm{m}^{3} \mathrm{~s}^{-1}\right]$ for the stripping flow to and from the headspace, and $A$ the surface area of the interface between the two phase the two fluxes are equal when

$A k_{O}\left(c_{l}-m_{l, g} \cdot c_{g}\right)=\Phi \cdot c_{g}$

or differently written when 
$\frac{c_{l}(t)}{c_{g}(t)}=m_{l, g}+\frac{\Phi}{A K_{O}}=m_{l, g}+\xi$

The dynamic "partition" parameter is related to an adjustment by the stripping transport ratio $\frac{\Phi}{A K_{O}}$.

This leads to a difference between aroma compounds of high and low $m_{l, g}$, relative to the stripping transport coefficient ratio. Changes in the system that have an effect on the rate of release, air flow or partition coefficient, may have different effects for different types of aroma compounds.

\subsection{Uses of aspects of mass transfer}

The three implications have been mentioned or studied before. Marin, Baek, and Taylor (2000) mentioned the first implication and investigated the third implication. Roos mentiones the first implication in relation to variations between dynamic and static measurements (de Roos, 2000; 2006a; 2006b) and uses it as an explanation for differences between in-vitro measurements of static partition coefficients and invivo measurements of dynamic release in the mouth (de Roos, 2006a, Fig 11.5) and measurements of CMS solutions in dynamic and static conditions (de Roos \& Wolswinkel, 1994). In his analysis, de Roos grouped the aroma compounds as either thermodynamically controlled (high $m_{l, g}$ compounds) or kinetically controlled (low $m_{l, g}$ compounds), however this is actually an effect of the third implication (stripping flow) that is not clearly separated.

The three implications are not used on a systematic basis and it may be useful to integrate them more strongly. If we are able to better express the mass transfer then we may also come up with better explanations for measurement results. We may do this by describing the aroma release by five parameters, the liquid/gas partition coefficient $m_{l, g}$, the gas-liquid volume ratio, $\beta=\frac{V_{g}}{V_{l}}$, the gas-liquid transport coefficients ratio, $\frac{k_{g}}{k_{l}}$, the time scale, $\tau=\frac{V_{g}}{k_{O} A}$, and the stripping mass transport ratio, $\xi=\frac{\Phi}{A K_{O}}$. All of them are directly related to the mass transfer rate.

\subsection{Inhomogeneity in the effect of viscosity on aroma release}

Many researchers have been studying some form of viscosity change and its effect on aroma release. We provide an overview of these studies (in Tables 1 and 2) in order to show that the discrepancies between these studies as well as aroma molecules can be classified into three categories which we will explain below. The studies are of different nature, for instance some are in vivo experiments. Yet it is remarkable that such a simple pattern arises and more thorough studies in the future may explain better if these patterns hold more generally, and can even be predicted. Also the classification shows that future studies should take better into account the different behaviour of molecules, which can be well ordered by the partition coefficient, and ensure that a wider range of molecules is tested.

We have summarized 22 studies in Table 1 . They can be classified into three different types: (A) The studies in the top of the table find decrease in aroma release when the viscosity is increased, (B) the studies in the middle find mixed results and depending on the type of aroma molecule there is a decrease or no change in aroma release when the viscosity is increased, (C) The studies in the bottom of the table find no change in aroma release when the viscosity is increased. Outside of this table we mention a study by Weel et al. (2004) who found an increase of aroma release when the viscosity is increased. In this study a throat model was used and an explanation may be that a higher viscosity resulted in more material remaining after swallowing.

In Table 2 the studies on the relation between viscosity and aroma release are placed on rows in a matrix. The columns in the matrix represent the aroma molecules that are used in the studies and they are ordered by Henry's coefficient determined with the experimental correlation in EPI-suite (US EPA, 2012) based on the bond contribution method. If an aroma is used in the study the cell associated with the column and row is coloured black for no effect and grey for a decrease of aroma release for increase in viscosity.

We can see that the studies with mixed results depending on aroma type have a similarity in the dependency of the partition coefficient. The release of aroma molecules with low $m_{l, g}$ are more often independent on the viscosity. This is in accordance with the low $m_{l, g}$ conditions in equation (7) $k_{O} \sim \frac{k_{g}}{m_{l, g}}$ and equation (9) $m_{a} \sim m_{l, g}+\beta$ that relate to a low dependence on changes in the liquid phase. The reverse is true for the release of aroma molecules with high $m_{l, g}$ which are more often dependent on the viscosity. This is in accordance with the high $m_{l, g}$ conditions in equation (7) $k_{O} \sim k_{l}$ and equation (9) $m_{a} \sim \xi+\beta$ that relate to a high dependence on changes in the liquid phase.

Out of the scope of the mathematical model presented in this review, but yet an interesting application for future studies of mass transfer indicated by Tables 1 and 2, are effects of mass transfer on invivo release. More specific the role of mass transfer in the discussion on the effect of an increased viscosity on a decreased perception in aroma intensity remains elusive. The results are inhomogeneous and the effects, why this inhomogeneity exists, if at all, has not yet been described fundamentally, or at least not into great detail or with wide application.

Several groups suggest that cognitive interactions with texture or other parameters may explain a reduced aroma perception with increased viscosity (Cook et al., 2003a; Hollowood et al., 2002; Kora et al., 2004; Weel, 2004). In support of this, Hort (2015) mentioned research (Bult, de Wijk, \& Hummel, 2007) in which the cognitive interaction is the subject itself and being tested by providing a ortho- or retronasal stimuli through the nose and separately from the ingested food product (milk) that is given a different thickness, but the effects on the perceived aroma intensity where not significant and also not repeated in more recent research (Iannilli et al., 2014). The effects of cognitive interactions may be present but they do not rule out that different aroma compounds, or concentration changes at other times or locations of consumption, are important as well.

\section{Mass transfer theories and models}

There is another aspect that makes a comparison and unification of different research results, and general application of findings, more difficult. The various engineering models of interfacial mass transfer are well described in standard text books for chemical engineering (Richardson, Harker, Coulson, \& Richardson, 2008, ch. 12; Welty, 2008, ch. 29), are also mentioned in several reviews on aroma release (Atlan, 2007; Cayot et al., 2008; de Roos, 2006a; Linforth, 2010), but they are not applied to their full extent. The application of models is mentioned in literature as a tool (Marin, Baek, \& Taylor, 1999, 2000; Banavara, Rabe, Krings, \& Berger, 2002; Parker \& Marin, 2000; Rabe, Krings, \& Berger, 2003a; Rabe, 2004; Atlan, 2007, ch. 1.2.3) but not as an objective of research by itself. In this section we shortly describe the mass transfer theories and models that have been used or mentioned in research on aroma release. Our goal is here to show the use in studies on aroma release and the potential for improved descriptions and understanding of mass transfer in aroma release.

\subsection{Theories of mass transfer across interfaces}

In Fig. 2 we provide a sketch of three different models summarized by Danckwerts and Kennedy (1954). In relation to the concentrations in the bulk $\left(c_{l}-m_{l, g} \cdot c_{g}\right)$ all the three models are similar and provide the same type of expression as in equation (6) with only a difference in the $k_{O}$ parameter. The models differ in the type of mechanism behind the mass transfer and result into mass transfer coefficients with a different dependency on the diffusion coefficient. Whitman's model assumes a laminar flow in a thin stagnant film layer near the boundary, of 
Table 1

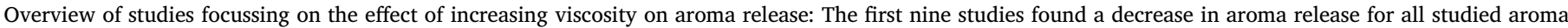

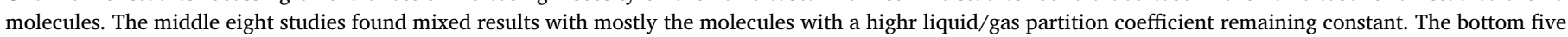
studies found no significant decrease in aroma release for all studies aroma molecules.

\begin{tabular}{|c|c|c|}
\hline reference & type of viscosity or gel strength change & type of aroma release measurement \\
\hline Baek, Linforth, Blake, and Taylor (1999) & 2,5 and $8 \%$ gelatine gels & 1st order fit release rate from 25 to $75 \%$ \\
\hline Marin et al. (2000) & water, 20 and $40 \%$ sucrose solutions & mass transfer coefficient in numerical fit \\
\hline Terta, Blekas, and Paraskevopoulou (2006) & various polysaccheride solutions & 1 st order fit initial release rate \\
\hline Seuvre, Philippe, Rochard, and Voilley (2007) & carbohydrate solution versus water & $\begin{array}{l}\text { 1st order fit initial release rate, time to } \\
\text { equilibrium }\end{array}$ \\
\hline Juteau-Vigier et al. (2007) & water and carrageenan matrices with different salt levels & diffusion coefficient in numerical fit \\
\hline Lubbers and Butler (2010) & water versus custards & 1st order fit initial release rate \\
\hline $\begin{array}{l}\text { Doyennette, de Loubens, Déléris, Souchon, and Trelea } \\
\text { (2011) }^{\text {(a) }}\end{array}$ & $0-70 \%$ sucrose solutions & mass transfer coefficient in numerical fit \\
\hline Déléris et al. (2011) ${ }^{(a)}$ & candies with $0-15 \%$ gelatine content & $\begin{array}{l}\text { peak time, peak concentration and area under } \\
\text { curve }\end{array}$ \\
\hline Samavati, Emam-Djomeh, and Mehdinia (2014) & $0-1.5 \%$ tragacanth gum solutions & 1 st order fit initial release rate \\
\hline Roberts, Elmore, Langley, and Bakker (1996) & thickener type, concentration & maximum aroma intensity \\
\hline de Roos (2000) & water versus $1 \%$ carboxymethylcellulose solution & retention after $1 \mathrm{~h}$ stripping \\
\hline Secouard, Malhiac, Grisel, and Decroix (2003) & carbohydrate polymer solutions versus water & release after $4 \mathrm{~h}$ \\
\hline Bylaite, Adler-Nissen, and Meyer (2005) & xanthan concentration & 1st order fit initial release rate \\
\hline Boland, Delahunty, and Vanruth (2006) (a) & gelatine and pectine concentrations & peak time and peak concentration \\
\hline Saint-Eve (2006) (a) & variations in mechanical treatment of yoghurt & peak aroma intensity after swallow \\
\hline Seuvre, Philippe, Rochard, and Voilley (2006) & carbohydrate solution versus water & 1st order fit initial release rate \\
\hline Siefarth et al. (2011) & different polyols & peak aroma intensity \\
\hline Hollowood, Linforth, and Taylor (2002) (a) & hydroxy propyl methylcellulose solutions & 1st and 2 nd breath aroma concentrations \\
\hline Cook, Hollowood, Linforth, and Taylor (2003a) (a) & solutions with various thickeners and concentrations & $\begin{array}{l}\text { aroma concentration in first and multiple breath } \\
\text { exhalations }\end{array}$ \\
\hline Cook, Linforth, and Taylor (2003b) (a) & solutions with various thickeners and concentrations & maximum and total concentrations \\
\hline Weel (2004, Ch. 6) (a) & $4-11 \%$ whey protein isolate gels & peak time and peak concentration \\
\hline Kora, Souchon, Latrille, Martin, and Marin (2004) & $\begin{array}{l}\text { variations in mechanical treatment of yoghurt and thickener } \\
\text { addition }\end{array}$ & 2nd order fit release rate coefficient \\
\hline
\end{tabular}

(a) These studies measured specifically in-vivo release.

thickness $\Delta x$. In Higbie's and Danckwert's model the layer near the boundary is assumed to be dynamic with small volume elements from the bulk replacing the fluid near the surface. The models differ in the scaling of the mass transfer coefficient on the diffusion coefficient. In Whitmans models $k_{l} \propto D$ and in Higbie's and Danckwert's models $k_{l} \propto D^{0.5}$. A difference between Higbie's and Danckwert's models is the description how the small volume elements near the surface are replaced by volume elementls from the bulk. In Higbie's model each volume element spends equal time, $\Delta t$, near the surface and in
Danckwert's model the volume elements are refreshed randomly, based on an average refreshment rate, $s$.

It is out of our scope to explain these models much further. While some reports on aroma release mention the use of a particular model, there is in practice no strong differentiation with other models. The three models do not mention a mechanism to determine the underlying parameters $\Delta x, \Delta t$ or $s$ and also all three models are simplifications. All three models are in essence similar scaling relations, in which the exact absolute numbers still have to be determined experimentally (see later

Table 2

Inhomogeneity in the effect of viscosity on aroma release for different studies and different aroma molecules.

口: In this study and for this aroma molecule there was no significant decrease in aroma release as a function of increasing viscosity.

I: In this study and for this aroma molecule there was a significant decrease in aroma release as a function of increasing viscosity.

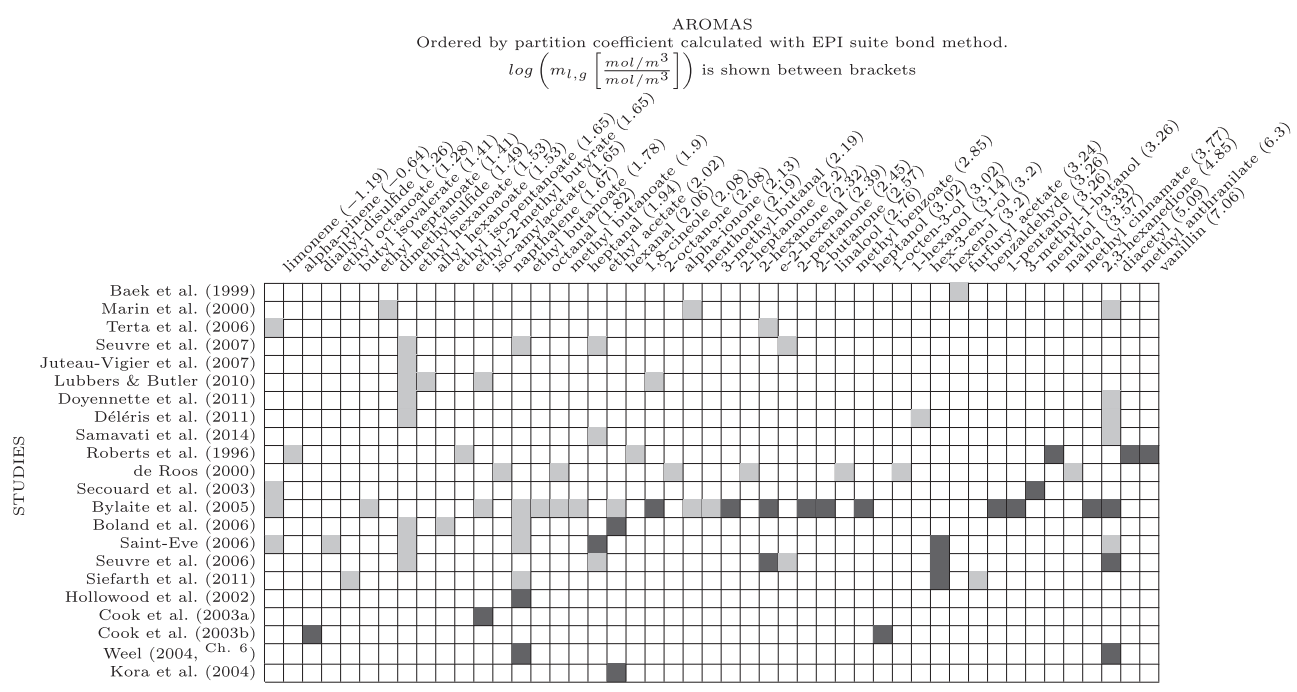




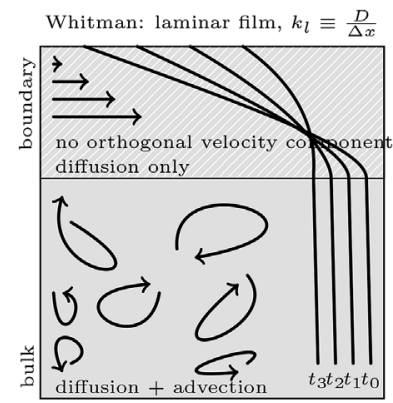

(a) Whitman's model has a laminar layer of thickness $\Delta x$ in which there is no vertical velocity component and only transport due to diffusion.

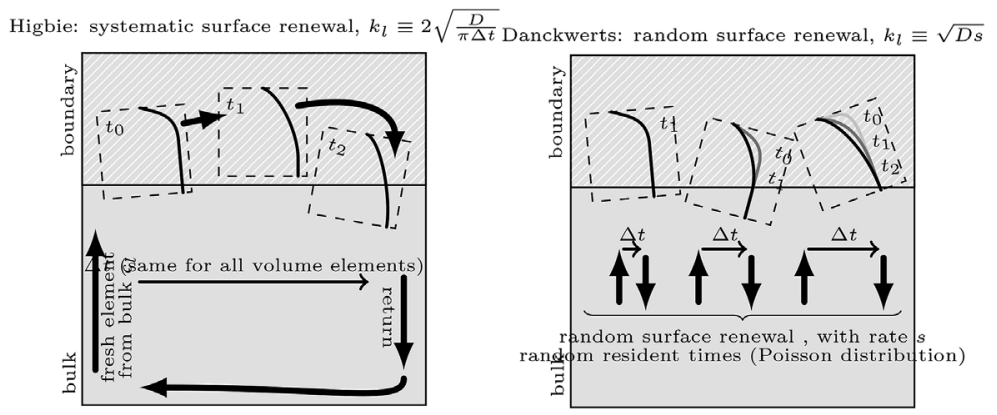

(b) In Higbie's model the layer is not stagnant. Distinct volume elements remain a time $\Delta t$ at the surface. The concentration profile is not constant and penetrates into the volume element. For longer residence times the rate of mass transport decreases. (c) Danckwerts model uses a refreshment rate $s$. The elements have a random residence time. this results in a slightly different expression compared to Higbie's model.

Fig. 2. Schematic drawing of three models of interfacial mass transfer (Danckwerts \& Kennedy, 1954).

discussion of equations (14) and (15)). However, the models give intuitive insight. In this respect there is an interesting modification to the models of Higbie and Danckwerts, with relevance to aroma release. Marchello and Toor (1963) created a 'film-penetration' model that is a combination of both Whitman's stagnant layers and Higbie's and Danckwerts dynamic layers. In the surface renewal theories some elements may remain at the surface so long and become so depleted that the penetration reaches a limit and they start to behave as Whitman's stagnant layers. The volume elements have then a mixed behaviour with the element with longer residence times behaving as Whitman's model and the elements with shorter residence times behaving as Higbie's or Danckwerts model.

A more complicated model will predict different effects for different aroma compounds. The less volatile molecules have a lower rate of transfer but reach equilibrium earlier, both resulting into a smaller depth of penetration. The more volatile compounds do reach a larger depth of penetration and for these compounds more elements with long residence times exist than elements with short residence times. In this case, a reduction of elements with longer residence time, by changes in $\Delta t$ or $s$ due to changes in flow conditions, will have different effects depending on the volatility of molecules. Knowing with what model one deals in a certain system and how it interacts with physicochemical properties of aroma compounds may help to better understand distortion of food aroma profiles, but it is difficult to investigate these models experimentally.

\subsection{Uses of dimensionless numbers}

We mentioned before that studies on the influence of viscosity on aroma release differ in results (see Tables 1 and 2). The dimension of the measurement, may play a role as well in these variable findings. When investigating release of aroma in the mouth, some researchers use shear rate as a reference for connecting in-vitro studies with in-vivo studies or sensory studies (Lubbers \& Butler, 2010; Roberts et al., 1996). However this may not be a proper parameter for comparisons since it is not a dimensionless number and may not provide similar results at different scales. For example the shear rate $\propto v / L$ does not differentiate between a turbulent state and laminar state of fluid flow, which is instead dependent on the Reynolds number $\propto v \cdot L$ and has an entirely different relation with the size, $L$, of the geometry. The description of conditions in aroma release with the use of shear rate, a less general principle, may result in different results among researchers in aroma release, and results that are difficult to compare.

Chemical engineers, working on application of mass transfer, often use the Reynolds, Sherwood and Schmidt numbers to express the relationship between the mass transfer coefficient and other parameters as flow velocity, boundary layer thickness and diffusivity. The dimensionless numbers that are used in this work are

\begin{tabular}{|c|c|c|}
\hline Re (Reynolds number) & $\frac{\rho v L}{\mu}$ & kinetic forces: viscous forces \\
\hline Sh (Sherwood number) & $\frac{k L}{D}$ & $\begin{array}{l}\text { effective mass transfer: diffusive mass } \\
\text { transfer }\end{array}$ \\
\hline Sc (Schmidt number) & $\frac{\mu}{\rho D}$ & viscous/kinetic transport: mass transport \\
\hline$\beta$ (gas/liquid volume ratio) & $\frac{V_{g}}{V_{l}}$ & gas volume: liquid volume \\
\hline $\begin{array}{l}\xi \text { (stripping transport coefficient } \\
\quad \text { ratio) }\end{array}$ & $\frac{\Phi}{k_{O} A}$ & $\begin{array}{l}\text { gas flow mass transport: overall interfacial } \\
\text { mass transport }\end{array}$ \\
\hline $\begin{array}{l}\frac{k_{g}}{k_{l}} \text { (gas/liquid mass transport c- } \\
\text { oefficient ratio) }\end{array}$ & $\frac{k_{g}}{k_{l}}$ & $\begin{array}{l}\text { gas film mass transfer coefficient: liquid } \\
\text { film mass transfer coefficient }\end{array}$ \\
\hline $\begin{array}{c}\mathrm{Fo}_{m}=\frac{t}{\tau} \text { (dimensionless time or } \\
\text { mass Fourier number })\end{array}$ & $\frac{k_{O} A}{2 V_{g}} t$ & time: filling time scale of gas volume \\
\hline $\begin{array}{c}C_{l} \text { (dimensionless aroma con- } \\
\text { centration in the liquid) }\end{array}$ & $\frac{c_{l}(\tau)}{c_{l}(0)}$ & $\begin{array}{l}\text { liquid aroma concentration at time } \tau \text { : at } \\
\text { time } 0\end{array}$ \\
\hline $\begin{array}{c}C_{g} \text { (dimensionless aroma con- } \\
\text { centration in the gas) }\end{array}$ & $\frac{c g(\tau)}{c_{l}(0)}$ & $\begin{array}{l}\text { gas aroma concentration at time } \tau \text { : liquid } \\
\text { at time } 0\end{array}$ \\
\hline
\end{tabular}

Recently, only a few research groups (Marin et al., 1999; Parker \& Marin, 2000; Banavara et al., 2002; Rabe et al., 2003a, b; Rabe, 2004) have used dimensionless numbers and correlations to express or investigate mass transfer coefficients in aroma release. ${ }^{1}$ The approaches have been different with variations in the type of correlation and variations in the part of the system (liquid phase or gas phase) for which the mass transfer coefficient has been described.

In all the cases the used mass transfer correlation was originally applied to a different situation, namely to mass transfer from walls to a flowing medium inside a tube. Marin et al. (1999) used mass transfer correlations to describe the mass transfer coefficient in the gas phase. The used equations were the Colburn equation for turbulent flow and the Levêque equation for laminar flow. Parker and Marin (2000) used mass transfer correlations to describe the mass transfer coefficient in both the gas phase and liquid phase. They used the Levêque equation for describing mass transfer at different flow rates for the liquid and gas phase in a laminar flow regime. Banavara et al. (2002); Rabe et al. (2003a, b); Rabe (2004) used mass transfer correlations to describe the mass transfer coefficient in both the gas and liquid phase. Their

\footnotetext{
${ }^{1}$ McNulty and Karel (1973) used relations with dimensionless numbers as well, but they studied mass transfer between oil and water.
} 

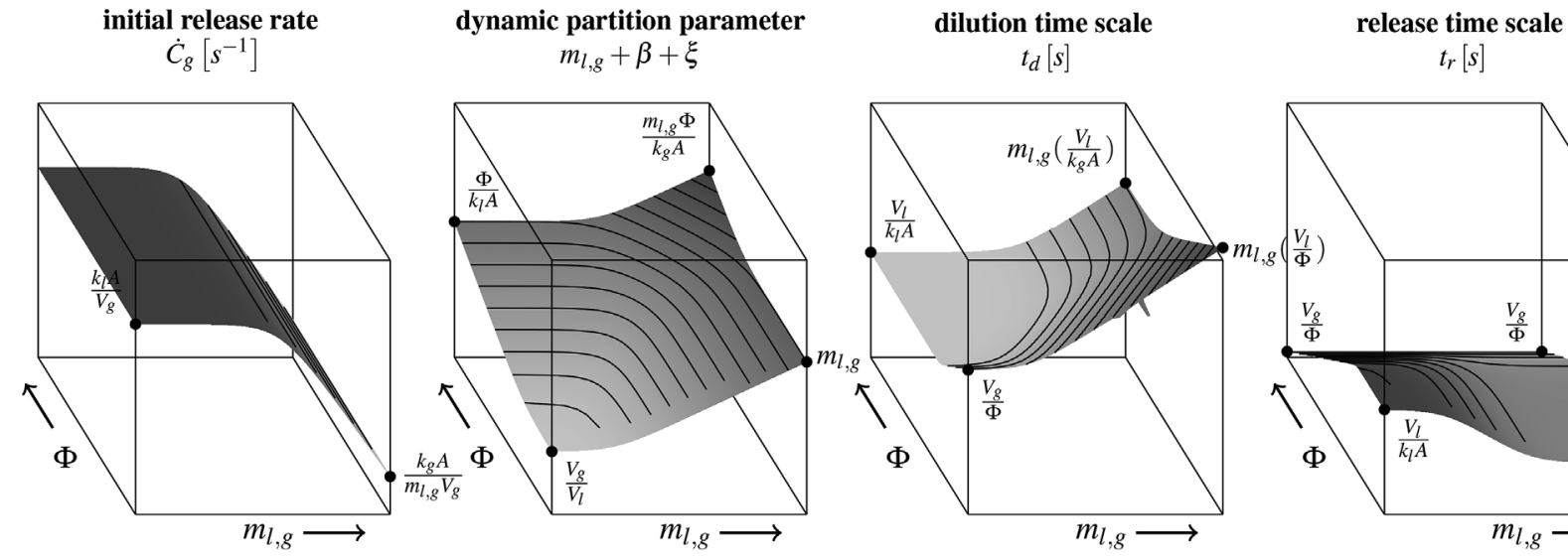

$t_{r}[s]$

Fig. 3. Plot of four aroma release attributes as a function of the liquid/gas partition coefficient $10^{-1}<m_{l, g}<10^{7}$ and the stripping rate $10^{-1} k_{l} A<\Phi<10^{6} k_{l} A$. The other parameters are kept constant (Used values are: $k_{g}=10^{-3}[\mathrm{~m} / \mathrm{s}], k_{l}=10^{-6}[\mathrm{~m} / \mathrm{s}], V_{g}=88[\mathrm{ml}], V_{l}=17[\mathrm{ml}]$ and $A=4.9\left[\mathrm{~cm}^{2}\right]$ ).

equation is a rough adaptation from the mass transfer equivalent of the Colburn equation (heat transfer from walls to a flowing medium inside a tube) described in Cussler (2009).

$k=0.026 \operatorname{Re}^{0.8} \operatorname{Sc}^{\frac{1}{3}} \frac{P}{H_{l n}}$

Where they use $H_{l n}$ as the logarithmic mean of the distance and a permeability term $P$ that is related to, among others, the square root of vapour pressure of a pure compound divided by solubility in water. By using this parameter $\mathrm{P}$ they actually introduce the Henrys coefficient into the rate of mass transfer, a dependency that already exists without considering theories of mass transfer as explained in section 3.

None of this research experimentally verified the correlation for aroma release by varying the Reynolds and Schmidt numbers. Marin et al. (1999) made no experimental variation of the Reynolds number, or at least this experimental variation was not reported. Two different Reynolds numbers, 500 and 25000, were used for calculating two different theoretical mass transfer coefficients, and only a comparison was made to determine which flow state most resembles the observations. In Marin et al. (2000) two models, based on a diffusion coefficient and based on a mass transfer coefficient, were tested. The diffusion coefficient was estimated for tests of aroma release from aqueous solutions with variable concentration in sucrose. The diffusion coefficient related to the viscosity of these solutions and showed agreement with the Stokes-Einstein relation. Parker and Marin (2000) did make changes to the flow rates of both the gas phase and the liquid phase, yet only in a small range. The estimated mass transfer coefficient, as a function of the increase in the flow rate, was slightly higher in the liquid phase but much higher (equal to linear response with the flow rate rather than the Levêque power law equation with a coefficient of 0.33 ) in the gas phase. Banavara et al. (2002); Rabe et al. (2003a, b); Rabe (2004) made no evaluation of their newly introduced correlation by varying conditions. They concentrated on variability due to the food matrix composition rather than variability due to properties of the interface and the relation to flow properties of the liquid and gas in the system, which they kept fixed using only a single setting (Re 50000).

It may be useful to test more general relations by systematically varying Reynolds and Schmidt numbers. The hypothesis is that we can relate results with a generalized Gilliland-Sherwood type correlation (Gilliland \& Sherwood, 1934) of the form:

$S h \propto R e^{m} S c^{n}$

where $m$ and $n$ are parameters that need to be determined experimentally. It is out of the scope of this paper to fully explain these relationships in more depth. However it is worthwhile to point out that there is currently a limited use of these equations and the type of equations that are used may not be right or at least not the best.
Meanwhile there is a much wider scope of research and information available in relation to mass transfer in absorption processes. Summaries of results in this research have been provided by Kozinski and King (1966) and Biń (1984) which show a range of the power law coefficient on the Reynolds number from 0.75 to 1.5 in the case of the mass transfer coefficient in the liquid phase of a stirred vessel. These results indicate that there may be improvement in the application of mass transfer correlations, beyond the application of Levêque and Colburn correlations.

\section{A classification scheme}

In this section we propose a scheme to classify different behaviour of aroma release based on the model description described in the previous sections. The scheme summarizes and simplifies the implications of the mathematical model and mass transfer theories without losing validity. The goal is to enable food scientists and technologists to apply the complex description in shorter and simpler terms that can be communicated and compared more easily. Simplified equations are provided, which allow a quantitative description of systems in regions of limiting cases with asymptotic behaviour. In this way the effects of mass transport in different situations can be assessed more readily in a quantitative way without a need to apply the full scale calculations.

\subsection{Aroma release curve attributes as function of partition coefficient and stripping factor}

Different attributes of aroma release curves can be used to describe the process of aroma release: (A) the initial release rate, (B) the peak value, (C) the release time scale and (D) dilution time scale. These properties also appear in the overview of different studies in Table 1 in properties such as peak heights, peak times, maximum intensity, or 2nd order fits. Currently these attributes are used differently among various studies and makes it difficult to compare results.

Fig. 3 shows an intuitive map of the expected behaviours of the aroma release curve attributes, as a function of two parameters, one thermodynamic, and one kinetic. The thermodynamic parameter of relevance is the liquid/gas partition coefficient, while the kinetic parameter is the flow rate relative to the velocity of transfer, as characterised bx $\xi=\frac{\Phi}{k_{l} A} .^{2}$

\footnotetext{
${ }^{2}$ In Fig. 3 we draw the axis with $\Phi$ rather than the dimensionless parameter $\xi$. One reason is that the parameter $\Phi$ is more commonly known in applications while $\xi$ is a combination of factors including the relationship $\frac{1}{k_{O}}=\frac{1}{k_{l}}+\frac{m_{l, g}}{k_{g}}$. A second reason is that the kinetic parameter $\xi$ itself incorporates an influence from the thermodynamic parameter $m_{l, g}$ and plotting it on an axis perpendicular
} 
The thermodynamic parameter is the liquid/gas partition coefficient, which is often used to describe the behaviour of aroma release. Components with high volatility and/or low solubility have a stronger affinity for the gas phase and are expected to release more strongly from the liquid to the head space.

In addition to the thermodynamic parameter we use a kinetic parameter, which we name the stripping factor. The kinetic parameter is the parameter $\xi=\frac{\Phi}{k_{O A} A}$ the rate of stripping in relation to the rate of mass transfer across the interface. In those cases with less well defined air flow conditions, a stripping flow, which can be quantified very well in controlled experiments, can be interpreted in qualitative terms. The stripping factor modifies the relationship between the four properties and the thermodynamic parameter. This modifying relationship creates an additional mode to explain variations in aroma release among different experiments and among different molecules. In the plots the term $\frac{\Phi}{k_{l} A}$ is used, with a dependence on the liquid side mass transfer coefficient $k_{l}$, rather than the overall mass transfer coefficient $k_{O}$. This is done because the overall mass transfer coefficient is strongly dependent on the thermodynamic parameter $m_{l, g}$ via the expression for the two film model $k_{O}=k_{l}\left(1+m_{l, g} \frac{k_{l}}{k_{g}}\right)^{-1}$. The liquid mass transfer coefficient changes less as a function of the type of aroma molecule.

The functions that describe the aroma release curve attributes are described by more parameters than just the a single mechanical and a single thermodynamic parameter. However it is the two dimensional scheme with these two parameters that captures the non homogeneous or non-linear behaviour in variations of the four aroma release curve attributes. The four surfaces in Fig. 3 are drawn by varying the values for the partition coefficient $m_{l, g}$ and the flux of stripping air $\Phi$, while keeping the other values fixed (Used values are: $k_{g}=10^{-3}[\mathrm{~m} / \mathrm{s}]$, $k_{l}=10^{-6}[\mathrm{~m} / \mathrm{s}], V_{g}=88[\mathrm{ml}], V_{l}=17[\mathrm{ml}]$ and $A=4.9\left[\mathrm{~cm}^{2}\right]$, where the latter values are based on the experimental set up as presented in Weterings et al. (in prep.)). The effects of these individual variables can be found in the expressions for the asymptotic behaviour, which are drawn in the corners of each diagrams. With a different set of fixed variables, the illustration keeps its general shape and only a translation occurs that shifts the function to new positions of the corners in the diagram. For instance when the interface area is changed the initial release rate changes everywhere by the same factor $A$ and the surface in the diagram shifts up or down.

\subsection{Initial release rate}

The initial release rate is shown in the first plot in Fig. 3 and describes the initial part of the aroma release curve which is approximately a linear function in time. The release rate can be derived by taking the derivative of the function 2 at time zero. The release rate found to be the ratio of the mass flux and the volume of the head space, and is equal to $\frac{k_{O} A}{V_{g}}$ (the inverse of the timescale $\tau_{g}$ ), where the overall mass transfer coefficient can be further expanded into a function of $k_{l}$ and $k_{g}$.

The initial release rate does not vary as a function of the kinetic parameter. In the diagram this non-variability is seen by the surface not changing in the direction of one of the axis, in this case the axis of the kinetic parameter. The stripping factor has no effect because initially the concentration in the head space is zero and there is no effective stripping taking place.

The initial release rate as a function of the thermodynamic parameter varies for low and high values of this parameter. The variation is

\section{(footnote continued)}

to $m_{l, g}$ would obscure this dependency (Eventually any choice of axes is a concession as the aroma release is determined by five parameters, $m_{l, g}, \beta, \xi, \frac{k g}{k_{l}}$ and $\tau$. It is eventually the equations for the asymptotic behaviour that fully capture all of the five parameters). due to a variation in the dominance of either the liquid or the gas side of interface. At low values of the liquid/gas partition coefficient, the liquid side dominates the mass transfer process, the initial release rate depends on the liquid phase mass transfer coefficient, and the initial release rate remains constant as function of the partition coefficient. At high values of the liquid/gas partition coefficient, the gas side dominates the mass transfer process, the initial release rate depends on the gas phase mass transfer coefficient, and the initial release rate is a linear decreasing function of the liquid/gas partition coefficient.

\subsection{Peak value or dynamic partition parameter}

The peak gas phase concentration is shown in the second plot in Fig. 3 and describes the maximum at which the head space aroma concentration reaches a peak value. In some experiments at short time scales and with little dilution this peak resembles a plateau. The peak or plateau value can be approximated and understood more easily by the value $m_{a}=m_{l, g}+\beta+\xi$, which we define as the dynamic partition parameter and which occurs in the scale factor of equation (2) determining the height of the aroma release curve equation. This relates to the' $m_{l, g}+\beta$ '-term that is often used in static head space analysis (Avison, van Gruijthuijsen, Pascu, Parker, \& Bodnár, 2015; Kolb \& Ettre, 2006). In the dynamic case we have an additional component, which is the stripping factor $\xi=\frac{\Phi}{k_{O} A}$. In many occasions one of these factors dominates and changes to the other factors have little effect in changing the peak or plateau level.

At low values of the stripping factor, ie very low gas stripping gas flow rates relative to the liquid-gas interfacial mass transfer rate, the liquid/gas peak value approaches the values for a static head space,' $m_{l, g}+\beta$ ', which equals the liquid/gas partition coefficient $m_{l, g}$ for high values of the liquid/gas partition coefficient and the gas/liquid phase ratio $\beta$ for low values of the liquid/gas partition coefficient. With little dominance of the stripping factor the variations in the stripping factor also have little effect on the peak value, which remains initially constant and nearly equal to values for the static head space aroma concentration.

At high values of the stripping factor the liquid/gas peak value becomes equal to the stripping factor $\xi=\frac{\Phi}{k_{O} A}$. For high values of the liquid/gas partition coefficient this value is dominated by the transport through the gas phase and becomes $\frac{m_{l, g} \Phi}{k_{g} A}$. For low values of the liquid/ gas partition coefficient this value is dominated by the transport through the liquid phase and becomes $\frac{\Phi}{k_{l} A}$

\subsection{Dilution time scale}

The dilution time scale is shown in the third plot in Fig. 3 and is the factor in the decreasing exponential term of equations (1) and (2). It is the parameter $\tau_{d}$ from equation (1) and describes the time necessary for this term to decrease to a level of one third $\left(e^{-1} \sim 1 / 3\right)$. The decreasing exponential term and the dilution time scale describe the depletion of aroma.

A part of the expression for $\tau_{d}$ can be understood in relation to the evacuation rate, which is the ratio of the stripping flux and the sample volume $\frac{\Phi}{V_{l}}$, and expresses the rate at which an amount of stripping air has passed that is equal to the liquid volume. The relative amount of stripping air that passes can be related to the relative amount of aroma that is stripped, by using expressions for the relative aroma concentration in the head space, or stripping air, in relation to the aroma concentration in the liquid. This occurs differently as a function of the chemical and kinetic parameters.

At low values of the stripping factor and high liquid/gas partition coefficient, the dilution time scale is an increasing function of the liquid partition coefficient and a decreasing function of the stripping factor. This dependency is related to the head space aroma concentration being nearly at equilibrium with the head space and determined by the 


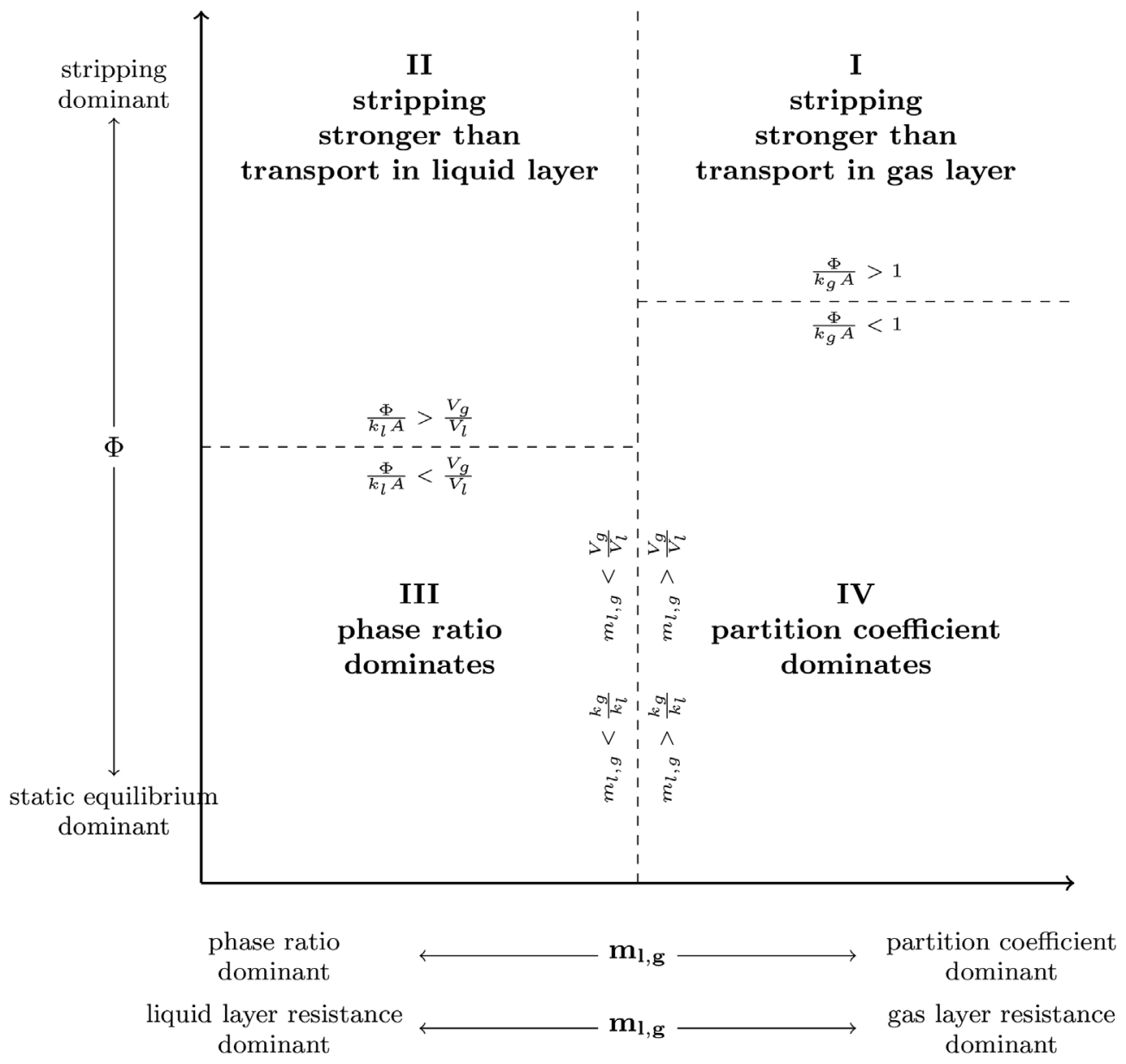

Fig. 4. Classification of aroma release according to the liquid/gas partition coefficient $m_{l, g}$ and the stripping rate $\Phi$.

liquid/gas partition coefficient. This principle is used in the stripping method to determine the partition coefficients (Lerol, Masson, Renon, Fabries, \& Sannier, 1977). In the stripping method a gas is bubbled through the a liquid, which is assumed to attain equilibrium with the gas (valid with a low stripping factor). The dilution rate is then measured and can be related to this equilibrium, the liquid/gas partition coefficient.

At low values of the stripping factor and low liquid/gas partition coefficient, the dilution time scale is a linear function of the liquid partition coefficient, and a decreasing function of the stripping factor. The dilution time scale becomes independent of the partition coefficient since the head space aroma concentration is related to the gas/liquid phase, rather than the partition coefficient, when a relatively large fraction of the total aroma partitions in the head space.

At high values of the stripping factor the dilution time scale becomes independent of the stripping factor (an asymptote is reached). This occurs when the aroma concentration in the head space is far away from the static equilibrium value. In this situation the concentration in the head space is relatively low and the mass transport by stripping is related to the mass transport over the interface at maximum concentration gradient. The intuition behind the value of the dilution time scale in this regime is very similar to the initial release rate. The dilution time scale becomes the ratio of volume of the liquid sample and the mass flux, $\frac{V_{l}}{k_{O A} A}$. Again, this value can be further expanded into a function of $k_{l}$ and $k_{g}$.

\subsection{Release time scale}

The release time scale is shown in the fourth plot in Fig. 3 and is the factor in the increasing exponential term of equations (1) and (2). It is the parameter $\tau_{r}$ from equation (1) and describes the time necessary for this term to decrease to a level of one third $\left(e^{-1} \sim 1 / 3\right)$. The increasing exponential term and the release time scale describe the increase of aroma in the head space. The release time scale is how long it takes for the head space aroma concentration to get two thirds closer to the peak value.

This fourth parameter can be understood as dependent on two other parameters: the release time scale can be equated to the peak value and the initial release rate, being the ratio of the two. In this view the release time scale is the time necessary to reach the peak value $m_{a}=m_{l, g}+\beta+\xi$ if the release rate would remain equal to the initial release rate. In reality the release rate decreases as time passes and does not remain equal to the initial release rate. Then after a unit of $\tau_{r}$ time has passed, instead of reaching the peak value, we get a factor 0.63 or two thirds closer to the peak value.

The release time scale is a constant function of the liquid/gas partition coefficient for either low an high values of the partition coefficient. At low values of the stripping factor a difference exists in a shift from a dominance by the liquid phase mass transfer coefficient for low values of the liquid/gas partition coefficient to a dominance by the gas phase mass transfer coefficient for high values of the liquid/gas partition coefficient. Also, at low values of the liquid/gas partition coefficient the release time scale depends on the liquid volume and relates to the time scale of decrease in the aroma concentration of the liquid bulk phase until the peak value is reached. And at high values of the liquid/ gas partition coefficient the release time scale depends on the gas volume and relates to the time scale of increase in the aroma concentration of the gas bulk phase until the peak value state is reached. 
At high values of the stripping factor the release time scale becomes independent of the stripping factor. This decrease is related to a decrease in the peak value, while the release rate does not change. The release time scale becomes shorter because the head space fills up to a lower aroma concentration level. These are the only values that are independent of the mass transfer coefficient. If the mass transfer coefficient rate increases then both the mass transfer rate and the peak value increase, such that the ratio remains the same.

\subsection{Four classes}

Four classes emerge, which can be used to express the variation in behaviour of different systems. In Fig. 4 the classes are described in terms of thermodynamic and kinetic parameters, respectively the stripping flow, $\Phi$ and the liquid/gas partition coefficient, $m_{l, g}$. The partition coefficient has been used before to classify aroma molecules. However, the stripping flow is used much less often. Also, the partition coefficient has mostly been used to classify aroma molecules on a linear and regular scale. This contrasts with the models in Fig. 3. In these models a two-dimensional scheme emerges and the function of the different aroma release attributes follow a variable and non-linear pattern, as function of partition coefficient.

The classification can be made according to the quadrants in the $\Phi-m_{l, g}$-plot of Fig. 4 and are:

- I Stripping Stronger than Transport in Gas Layer

- II Stripping Stronger than Transport in Liquid Layer

- III Phase Ratio Dominates

- IV Partition Coefficient Dominate

The variation between the quadrants II and III on the left and I and IV on the right is defined by two inequalities or balance between factors. In the left quadrants I and IV the partition coefficient $m_{l, g}$ is higher than both the mass transfer ratio $\frac{k_{g}}{k_{l}}$ and the volume ratio $\frac{V_{g}}{V_{l}}$. If the value of the partition coefficient is lower than these values then the liquid layer resistance and the phase ratio become more dominant.

The variation between the quadrants I and II on the top and III and IV on the bottom is defined by one inequality or balance between factors. In the top quadrants I and II the stripping flow $\Phi$ is so high that it dominates the static equilibrium values in determining the head space aroma concentration. The balance is based on the relation between the stripping rate $\Phi$ and the overall mass transfer rate $k_{O} A$. A difference in this balance occurs at various partition coefficients because the partition coefficient influences the overall mass transfer rate, which is dominated by the transport in the liquid film layer for low $m_{l, g}$, and dominated by the transport in the gas film layer for high $m_{l, g}$.

\subsection{Simplified equations}

For each class a set of simplified equations can be applied. These equations are shown in Table 3 in a $4 \times 4$ matrix with each cell an equation that relates to a class, depicted by a row, and a aroma release attribute, depicted by a column. Two additional columns are descriptors of the class in terms of the parameters $\Phi$ and $m_{l, g}$. In Fig. 3 the equations are placed at the corners of the sketches and relate to the values of the asymptotic behaviour of the aroma release attributes in the four different classes. The equations are based on asymptotic behaviour of the full equation (2). In this subsection we work out two cases.

The use of the classification and simplified equations can be explained by a thought experiment. We consider the optimization of a strawberry flavour in a yoghurt and a soda drink with respect to a changed viscosity due to a change in product reformulation. The impact of the aroma is assumed to be related to the initial release rate and the peak value of the parameter $\tau_{d}$ from equation (1) aroma and the
Table 3

Simplified expressions, derived from the full equation (2) for aroma release, for approximate values of the height of the aroma release curve, the initial release rate, the release time scale and the dilution time scale. The expressions for these values are different in the four classes that depend on the chemical and mechanical characterization of the aroma release.

\begin{tabular}{lllllll}
\hline system & $\begin{array}{l}\text { liquid/gas } \\
\text { partition } \\
\text { coeffficient }\end{array}$ & $\begin{array}{l}\text { mechanical } \\
\text { stripping } \\
\text { factor }\end{array}$ & $\begin{array}{l}\text { initial } \\
\text { release } \\
\text { rate }\end{array}$ & peak value & $\begin{array}{l}\text { dilution } \\
\text { time } \\
\text { scale }\end{array}$ & $\begin{array}{l}\text { release } \\
\text { time } \\
\text { scale }\end{array}$ \\
\hline$m_{l, g}$ & $\frac{\Phi}{k_{l} A}$ & $\dot{C}_{g}$ & $m+\beta+\xi$ & $\tau_{d}$ & $\tau_{r}$ \\
I & high & high & $m_{l, g} \frac{k_{g} A}{V_{g}}$ & {$\left[m_{l, g} \frac{\Phi}{k_{g} A}\right]^{-1}$} & $m_{l, g} \frac{V_{l}}{k_{g} A}$ & $\frac{V_{g}}{\Phi}$ \\
II & low & high & $\frac{k_{l} A}{V_{g}}$ & {$\left[\frac{\Phi}{k_{l} A}\right]^{-1}$} & $\frac{V_{l}}{k_{l} A}$ & $\frac{V_{g}}{\Phi}$ \\
III & low & low & $\frac{k_{l} A}{V_{g}}$ & {$\left[\frac{V_{g}}{V_{l}}\right]^{-1}$} & $\frac{V_{g}}{\Phi}$ & $\frac{V_{l}}{k_{l} A}$ \\
IV & high & low & $m_{l, g} \frac{k_{g} A}{V_{g}}$ & {$\left[m_{l, g}\right]^{-1}$} & $m_{l, g} \frac{V_{l}}{\Phi}$ & $\frac{V_{g}}{k_{g} A}$ \\
\hline
\end{tabular}

question is how to adjust the aromatic components to generate a balanced flavour.

The yoghurt: has a high viscosity and is expected to have a low rate of mass transfer in the liquid film (resulting in large stripping factor). An estimation for the mass transfer ratio would be above the level $\frac{k_{g}}{k_{l}}>10^{3}$ or $10^{4}$. Many of the components of the strawberry aroma (those with $m_{l, g}<\frac{k_{g}}{k_{l}}<10^{3}$ ) fall into class II (low $m$ and tends to be strong). An influence of viscosity on $k_{l}$ will influence the initial aroma release rate $\dot{C}_{g} \sim \frac{k_{l} A}{V_{g}}$ and peak aroma concentration level $m_{l, g}+\beta+\xi \sim \frac{\Phi}{k_{l} A}$. Only few components (those with $m_{l, g}>\frac{k_{g}}{k_{l}}>10^{4}$ ) fall in a different class I or IV and are unaffected by the viscosity changes in the product reformulation. Thus, from the classification model it can be deduced that viscosity has a strong impact on a large set of aroma molecules and attributes associated with top and middle note molecules, high to intermediate volatility, such as fruitiness and freshness are unstable to viscosity changes requiring extra attention.

The soda: has a low viscosity, additional transport by bubbles, and is expected to have a high rate of mass transfer in the liquid film. An estimation for the mass transfer ratio would be at the level $\frac{k_{g}}{k_{l}} \sim 10^{1}$. Only few components (those with $m_{l, g}<\frac{k_{g}}{k_{l}} \sim 10^{1}$ ) fall in a different class II or III and are affected by the viscosity changes in the product reformulation. Most components (those with with $m_{l, g}>\frac{k_{g}}{k_{l}} \sim 10^{1}$ ) fall into class IV and do not depend much on the effects of viscosity with viscosity stable levels for the initial release rate $\dot{C}_{g} \sim \frac{k_{g} A}{m_{l, g} V_{g}}$ and dynamic aroma concentration level $m_{l, g}+\beta+\xi \sim m_{l, g}$. Thus, from the classification model it can be deduced that viscosity has a limited impact on most of the aroma molecules and only a few high top note molecules, such as citrus notes or high molecular weight esters are unstable to viscosity changes requiring extra attention.

The stability of viscosity changes, the effect of parameter $k_{l}$, is mirrored by instability in partition coefficient changes $m_{l, g}$. For instance changes in temperature, effecting partitioning relatively more than liquid mass transport, have more effect in class I and IV, and reducing temperature of a soda drink increases the ratio top/base notes).

\section{Conclusions}

Mass transfer and the kinetics of aroma release have an important but complex role in aroma release. A full description of the mechanistic approach is stated with an alternative and more general derivation. We have shown that the description can be simplified with five dimensionless parameters, volume ratio, liquid/gas film mass transfer ratio, stripping transport coefficient ratio, partition coefficient, and a 
dimensionless time.

A summary and explanation is given of three implications of the model: the effect of the partition coefficient on the overall mass transfer coefficient, the effect of the partition coefficient on dominance of either saturation of the gas phase or dilution of the liquid phase, and a peak value different from the partition coefficient. These three effects do not appear simultaneously in other works and are not always easily taken into account. Using an overview of studies on correlations between viscosity, aroma type and release intensity we show that there is heterogeneity in the effect of viscosity among different aroma types and different experiments.

A classification scheme has been created that makes the mathematical description more accessible to food researchers and technologist.
The full description is approximated by simple but correct equations and classes. This classification provides a simplified view of a system and allows for easy comparing with results of other experiments or aroma's. Thermodynamic parameters, related to partition coefficient, and kinetic parameters, related to the stripping factor, play a combined role in the classification and description of aroma release. With the new classification we can now understand the previous found ambiguity from Table 2.

\section{Acknowledgements}

This study is part of a project funded by the Commission for Technology and Innovation (CTI) of Switzerland, grant no. 14936.1

\section{Appendix. Derivation of release curve equations}

The release of aroma is modelled by two film theory and by surface renewal theory (only a difference in the expression of the overall transport rate coefficient). For this model we obtain two coupled ordinary differential equations. These equations and their solutions have already been published before, most notably by the group of Harrison and Hills. We derive the equations here again in order to apply some simplifications. Also, while Harrison and Hills use a laplace transformation to solve the equations, we simply solve the equations by supposing a linear combination of exponential functions. This is a valid method for any set of coupled linear ordinary differential equations with constant coefficients. In fact, these type of differential equations have been described more generally as compartment models in the field of pharmacological sciences (Godfrey, 1983), and the solution to a compartmental model is a sum of exponents with an exponential term for each single compartment. The model described here is equivalent to a two-compartment model and will result in a sum of two exponents. Extensions would in principle be possible to extend to three (Normand et al., 2004), eight (Déléris et al., 2016) or other numbers.

In the model we consider two modes of transport:

A: a convective transport across the interfacial boundary layer between the liquid phase and the gas phase. The rate can be expressed in terms of the aroma concentration in the liquid phase, $c_{l}$, and the gas phase, $c_{g},-k_{O} A\left(c_{l}-m_{l, g} c_{g}\right)\left[\mathrm{mol} s^{-1}\right]$ (Welty, 2008, eq. (29)-10/11). in Fig. 1 we provided an intuitive view for the derivation of the overall mass transfer coefficient, $k_{O}$, as function of $m_{l, g}, k_{g}$ and $k_{l}$.

B: a small gas flow into and out of the system introduces an advection process in the gas phase. The transport rate is dependent on the concentration in the gas phase and on the flow of gas $\Phi c_{g}\left[\mathrm{~mol} \mathrm{~s}^{-1}\right]$. In the Harrison and Hills model this term is added to mimic the breathing during release of aroma in the mouth. In the analysis of in-vitro experiments the term can be used to describe a stripping flow that is used during the measurements. In food processing the term may relate to a loss factor due to leaks in the system or due to a systematic flow as in a drying process.

The changes of the liquid and gas bulk phase are then expressed by the following differential equations.

$\frac{d c_{l}}{d t}=\frac{-k_{O} A}{V_{l}}\left(c_{l}-m_{l, g} c_{g}\right)$

$\frac{d c_{g}}{d t}=\underbrace{\frac{k_{O} A}{V_{g}}\left(c_{l}-m_{l, g} c_{g}\right)}_{\text {interface transport }}-\underbrace{\frac{\Phi}{V_{g}} c_{g}}_{\text {gas flow transport }}$

The terms related to the transport across the interface and the transport due to the gas flow are underlined in the second equation. The parameters used are

liquid bulk concentration $=c_{l}\left[\mathrm{~mol} \mathrm{~m} \mathrm{~m}^{-3}\right]$

gas bulk concentration $=c_{g}\left[\mathrm{~mol} \mathrm{~m} \mathrm{~m}^{-3}\right]$

gas flow $=\Phi\left[\mathrm{m}^{3} \mathrm{~s}^{-1}\right]$

interface surface area $=A\left[\mathrm{~m}^{2}\right]$

liquid phase volume $=V_{l}\left[\mathrm{~m}^{3}\right]$

gas phase volume $=V_{g}\left[\mathrm{~m}^{3}\right]$

liquid/gas partitioning coefficient $=m_{l, g}\left[\frac{\mathrm{mol} m^{-3}}{\mathrm{~mol} \mathrm{~m}^{-3}}\right]=\frac{c_{l}^{e q}}{c_{g}^{e q}}$

overal transport rate coefficient $=k_{O}\left[m^{-1}\right] ; \quad \frac{1}{k_{O}}=\frac{1}{k_{l}}+\frac{m_{l, g}}{k_{g}}$

Simplifications with dimensionless parameters

We use the dimensionless parameters $m_{l, g}, \beta=\frac{V_{g}}{V_{l}}, \xi=\frac{\Phi}{k_{O} A}, F o_{m}=\frac{t}{\tau}=\frac{t k_{O} A}{V_{g}}, C_{l}=\frac{c_{l}(t)}{c_{l}(0)}$ and $C_{g}=\frac{c_{g}(t)}{c_{l}(0)}$ (described in section 4.2). Then equations (16) and (17) become as following

$\frac{d c_{l}}{d\left(F_{m}\right)}=\frac{d c_{l}}{d t} * \frac{V_{g}}{k A}=-\beta\left(c_{l}-m_{l, g} c_{g}\right)$

$\frac{d c_{g}}{d\left(F o_{m}\right)}=\frac{d c_{g}}{d t} * \frac{V_{g}}{k A}=\left(c_{l}-m_{l, g} c_{g}\right)-\xi c_{g}$

or further simplified (division by $c_{l}(0)$, and with $\cdot$ as the derivative in the dimensionless time $F o_{m}=t / \tau$ 
$\dot{C}_{l}=-\beta\left(C_{l}-m_{l, g} C_{g}\right)$

$\dot{C_{g}}=\left(C_{l}-m_{l, g} C_{g}\right)-\xi C_{g}$

\section{Solution with exponential functions}

The differential equations (18) and (19) are a set of coupled linear ordinary differential equations with constant coefficients. For such equations the general solution can be written in terms of a linear combination, using a basis of exponential functions

$\left(\begin{array}{l}C_{l}\left(F o_{m}\right) \\ C_{g}\left(F o_{m}\right)\end{array}\right)=\sum\left(\begin{array}{c}C_{l, s} e^{s F o_{m}} \\ C_{g, s} e^{s F o_{m}}\end{array}\right)$

where $C_{l, s}, C_{g, s}$ and $s$ are constants (respective to the time parameter). The possible values for $s$ (and the associated values for, or relation between, $C_{l, s}$ and $C_{g, s}$ ) can be determined by inserting a basis function, equation (20), into equations (18) and (19) and dividing by $e^{s t / \tau}$. This leads, with some rearrangements of terms, to the following two algebraic expressions:

$C_{l, s}=\frac{\beta m_{l, g}}{\beta+s} C_{g, s}$

$s^{2}+\left(\beta+\xi+m_{l, g}\right) s+\beta \xi=0$

equation (22) is a quadratic form and has two solutions for $s$ :

$s_{d}=-\frac{1}{2}\left(\beta+m_{l, g}+\xi-\sqrt{\left(\beta+m_{l, g}+\xi\right)^{2}-4 \xi \beta}\right)$

$s_{r}=-\frac{1}{2}\left(\beta+m_{l, g}+\xi+\sqrt{\left(\beta+m_{l, g}+\xi\right)^{2}-4 \xi \beta}\right)$

The complete solution is then of the form:

$\left(\begin{array}{c}C_{l}\left(F o_{m}\right) \\ C_{g}\left(F o_{m}\right)\end{array}\right)=A\left(\begin{array}{c}\frac{\beta m_{l, g}}{\beta+s_{r}} e^{s_{r} F o_{m}} \\ e^{s_{r} F o_{m}}\end{array}\right)+B\left(\begin{array}{c}\frac{\beta m_{l, g}}{\beta+s_{d}} e^{s_{d} F o_{m}} \\ e^{s_{d} F o_{m}}\end{array}\right)$

Here we use the terms $s_{d}$ and $s_{r}$, with subscripts $d$ and $r$, because they can be respectively related to a dilution process and a release process. The inverse of these values $\tau_{g} / s_{d}$ and $\tau_{g} / s_{d}$ are the time scales $\tau_{d}$ and $\tau_{r}$ used in Fig. 3 and equation (1).

With additional boundary conditions $C_{l}(0)=1$ and $C_{g}(0)=0$, all aroma is initially in the liquid phase, we can complete the equations (solving $A$ and $B$ ) and for $C_{g}(\tau)$ we get the solution which is equivalent to equation 2

$$
C_{g}(t)=\frac{c_{g}(t)}{c_{l}(0)}=\frac{e^{-\left(m_{a}-\sqrt{m_{a}^{2}-4 \xi \beta}\right) \cdot \frac{t}{\tau_{g}}}-e^{-\left(m_{a}+\sqrt{m_{a}^{2}-4 \xi \beta}\right) \cdot \frac{t}{\tau_{g}}}}{\sqrt{m_{a}^{2}-4 \xi \beta}}
$$

The two exponential terms relate to a release of aroma (the transport across the interface), and a dilution of aroma (the loss of aroma due to the gas flow).

\section{Approximate solutions}

equation (26) can be greatly simplified for special cases in which a particular parameter is relatively very low or high. In that case the square root term can be approximated using a Taylor or Laurent series and several terms cancel or can be neglected.

The approximation of the root term uses the following series expansion which converges for real numbers $|q| \leq|r|$

$$
\begin{gathered}
\sqrt{q+r}=r^{0.5} \sum_{n=0} \infty\left(\begin{array}{c}
0.5 \\
n
\end{array}\right)\left(\frac{q}{r}\right)^{n} \\
=r^{0.5}\left(1+\frac{1}{2}\left(\frac{q}{r}\right)-\frac{1}{8}\left(\frac{q}{r}\right)^{2}+\frac{1}{16}\left(\frac{q}{r}\right)^{3}+\ldots\right)
\end{gathered}
$$

We will now discuss what conditions give rise to the applicability of this approximation.

Small gas flow

In the case that the gas flow is small we have a low value for $\xi$. Let's consider the case:

$4 \xi \beta<<\left(\beta+m_{l, g}+\xi\right)^{2}$

Then we can use equation (27) with $q=4 \xi \beta$ and $r=\left(\beta+m_{l, g}+\xi\right)^{2}$ resulting in the following approximation for the root term in equation 26

$$
\begin{aligned}
\sqrt{\left(\beta+m_{l, g}+\xi\right)^{2}-4 \xi \beta} & =\left(\beta+m_{l, g}+\xi\right)+2 \frac{\xi \beta}{\beta+m_{l, g}+\xi} \\
+ & \mathcal{O}\left(\frac{\xi^{2}}{\beta}\right)
\end{aligned}
$$


And equation (26) becomes approximately:

$C_{g}\left(F o_{m}\right) \simeq \frac{1}{\beta+m_{l, g}} *\left(e^{-\frac{\xi \beta}{\beta+m_{l, g}} F o_{m}}-e^{-\left(\beta+m_{l, g}\right) F o_{m}}\right)$

For highly volatile molecules or large gas phase volumes $\left(m_{l, g}<<\beta\right)$ and the partition coefficient can be neglected in the term $\beta+m_{l, g}$. The release of relatively highly volatile molecules is similar and depends (approximately) only on the transport coefficient and gas flow:

$\lim _{m, g \rightarrow 0} C_{g}\left(F o_{m}\right)=\frac{1}{\beta} *\left(e^{-\xi F_{m}+}-e^{-\beta F o_{m}}\right)$

This is actually an expression of the effect that we discussed in section 3.3.

\section{Large gas flow}

If we use the expansion in 27 with the values $q=\beta^{2}+2 \beta m_{l, g}-2 \beta \xi$, and $r=\left(m_{l, g}+\xi\right)^{2}$, then we have convergence for all $m$ if $\frac{\xi}{\beta} \geq 1$. The approximation of the root term becomes:

$$
\begin{aligned}
& \sqrt{\left(\beta+m_{l, g}+\xi\right)^{2}-4 \xi \beta}=\left(m_{l, g}+\xi\right)+\frac{1}{2} \frac{\left(\beta^{2}+2 \beta m_{l, g}-2 \beta \xi\right)}{\left(m_{l, g}+\xi\right)} \\
& -\frac{1}{8} \frac{\left(\beta^{2}+2 \beta m_{l, g}-2 \beta \xi\right)^{2}}{\left(m_{l, g}+\xi\right)^{3}}+\mathcal{O}\left(\frac{\beta}{\left(m_{l, g}+\xi\right)^{2}}\right)
\end{aligned}
$$

If $\frac{\xi}{\beta} \gg 1$ then equation (2) becomes approximately:

$C_{g}\left(F o_{m}\right) \simeq \frac{1}{m_{l, g}+\xi} *\left(e^{-\left(\frac{\xi \beta}{m+\xi}\right) F o_{m}}-e^{-(\xi+m l, g) F o_{m}}\right)$

\section{References}

Atlan, S. (2007). Modelisation de la liberation des composes d'arome a partir de matrices alimentaires dans des systemes experimentaux et en bouche: Determination des proprietes et mecanismes de transfert de matiere. Phd institut national de la recherche agronomique.

Avison, S., van Gruijthuijsen, K., Pascu, M., Parker, A., \& Bodnár, I. (2015). Novel methodology for measuring temperature-dependent Henry's constants of flavor molecules. Journal of Agricultural and Food Chemistry, 63, 6313-6318. https://doi.org/ 10.1021/acs.jafc.5b01517.

Baek, I., Linforth, R., Blake, A., \& Taylor, A. J. (1999). Sensory perception is related to the rate of change of volatile concentration in-nose during eating of model gels. Chemical Senses, 24, 155-160.

Banavara, D. S., Rabe, S., Krings, U., \& Berger, R. G. (2002). Modeling dynamic flavor release from water. Journal of Agricultural and Food Chemistry, 50, 6448-6452. https://doi.org/10.1021/jf020232c.

Biń, A. K. (1984). Mass transfer to the free interface in stirred vessels. Chemical Engineering Communications, 31, 155-183.

Boelrijk, A. E. M., Smit, G., Weel, K. G. C., Burger, J. J., Voilley, A., Etiévant, P., et al. (2006). Flavor release from liquid food products. Flavor in Food, 260-284.

Boland, A., Delahunty, C., \& Vanruth, S. (2006). Influence of the texture of gelatin gels and pectin gels on strawberry flavour release and perception. Food Chemistry, 96, 452-460. https://doi.org/10.1016/j.foodchem.2005.02.027.

Bortnowska, G. (2010). Influence of thermodynamic and kinetic factors on the retention and release of aroma compounds in liquid food systems-A review. Polish Journal of Food and Nutrition Sciences, 60.

Bult, J. H., de Wijk, R. A., \& Hummel, T. (2007). Investigations on multimodal sensory integration: Texture, taste, and ortho- and retronasal olfactory stimuli in concert. Neuroscience Letters, 411, 6-10. https://doi.org/10.1016/j.neulet.2006.09.036.

Buttriss, J. L. (2013). Food reformulation: The challenges to the food industry. Proceedings of the Nutrition Society, 72, 61-69. https://doi.org/10.1017/S0029665112002868.

Bylaite, E., Adler-Nissen, J., \& Meyer, A. S. (2005). Effect of xanthan on flavor release from thickened viscous food model systems. Journal of Agricultural and Food Chemistry, 53, 3577-3583.

Cayot, N., Dury-Brun, C., Karbowiak, T., Savary, G., \& Voilley, A. (2008). Measurement of transport phenomena of volatile compounds: A review. Food Research International, 41, 349-362. https://doi.org/10.1016/j.foodres.2008.02.002.

Conde-Petit, B., Escher, F., \& Nuessli, J. (2006). Structural features of starch-flavor complexation in food model systems. Trends in Food Science \& Technology, 17, 227-235. https://doi.org/10.1016/j.tifs.2005.11.007.

Cook, D. J., Hollowood, T. A., Linforth, R. S., \& Taylor, A. J. (2003a). Oral shear stress predicts flavour perception in viscous solutions. Chemical Senses, 28, 11-23.

Cook, D. J., Linforth, R. S. T., \& Taylor, A. J. (2003b). Effects of hydrocolloid thickeners on the perception of savory flavors. Journal of Agricultural and Food Chemistry, 51, 3067-3072. https://doi.org/10.1021/jf0211581.

Coumans, W. J., Kerkhof, P. J., \& Bruin, S. (1994). Theoretical and practical aspects of aroma retention in spray drying and freeze drying. Drying Technology, 12, 99-149. https://doi.org/10.1080/07373939408959951.

Cussler, E. L. (2009). Diffusion mass transfer in fluid systems. Cambridge; New York:
Cambridge University Press.

Danckwerts, P. V., \& Kennedy, A. M. (1954). Kinetics of liquid-film process in gas absorption. Part I: Models of the absorption process. Transactions of the Institution of Chemical Engineers, 32, 49-52.

Delarue, J., \& Giampaoli, P. (2006). Carbohydrate-flavour interactions. In A. Voilley, \& P. Etiévant (Eds.). Flavour in foods (pp. 208-228). Cambridge: Woodhead Publishing Ltd.

Déléris, I., Saint-Eve, A., Dakowski, F., Sémon, E., Le Quéré, J.-L., Guillemin, H., et al. (2011). The dynamics of aroma release during consumption of candies of different structures, and relationship with temporal perception. Food Chemistry, 127, 1615-1624. https://doi.org/10.1016/j.foodchem.2011.02.028.

Déléris, I., Saint-Eve, A., Kauffmann, M., Feron, G., \& Souchon, I. (2015). Experimental approaches to better understand the retention of aroma compounds in oro-nasopharyngeal cavities. In American Chemical Society, B. Guthrie, J. Beauchamp, A. Buettner, \& B. K. Lavine (Vol. Eds.), The chemical sensory informatics of food: Measurement, analysis, integration: Vol. 1191, (pp. 147-170). Washington, DC: American Chemical Society.

Déléris, I., Saint-Eve, A., Saglio, A., Souchon, I., \& Trelea, I. C. (2016). Insights in aroma compound retention by mucosa during consumption through mathematical modelling. Journal of Food Engineering, 190, 123-138. https://doi.org/10.1016/j.jfoodeng. 2016.06.018.

Dolu, O. (2013). Characterization of protein-flavor interactions using inverse gas chromatography. Ph.D. thesis Rutgers University-Graduate School-New Brunswick.

Doyennette, M., de Loubens, C., Déléris, I., Souchon, I., \& Trelea, I. (2011). Mechanisms explaining the role of viscosity and post-deglutitive pharyngeal residue on in vivo aroma release: A combined experimental and modeling study. Food Chemistry, 128, 380-390. https://doi.org/10.1016/j.foodchem.2011.03.039.

Dumont, J. (2006). Emulsion-flavour interactions. In A. Voilley, \& P. Etiévant (Eds.). Flavour in foods (pp. 156-171). Cambridge: Woodhead Publishing Ltd.

Fisk, I. (2015). Aroma release. Flavour development, analysis and perception in food and beverages (pp. 105-123). Elsevier.

Gierczynski, I., Guichard, E., \& Laboure, H. (2011). Aroma perception in dairy products: The roles of texture, aroma release and consumer physiology. A review. Flavour and Fragrance Journal, 26, 141-152. https://doi.org/10.1002/ffj.2036.

Gilliland, E. R., \& Sherwood, T. K. (1934). Diffusion of vapors into air streams. Industrial and Engineering Chemistry, 26, 516-523.

Godfrey, K. (1983). Compartmental models and their application. London, England: Academic Press.

COST 96 - interaction of food matrix with small ligands influencing flavour and texture. In E. Guichard (Ed.). Vol. 6: [Contributions made at the meeting held in oslo (may 20 - 21, 1999)]. Number 19238 in EUR food science and technology. Luxembourg: Off. for Off. Publ. of the Europ. Communities.

Guichard, E. (2015). Interaction of aroma compounds with food matrices. Flavour development, analysis and perception in food and beverages (pp. 273-295). Elsevier.

Harrison, S. M., Cleary, P. W., Eyres, G., D. Sinnott, M., \& Lundin, L. (2014). Challenges in computational modelling of food breakdown and flavour release. Food Funct, 5, 2792-2805. https://doi.org/10.1039/C4FO00786G.

Harrison, M., \& Hills, B. (1997a). Effects of air flow-rate on flavour release from liquid emulsions in the mouth. International Journal of Food Science and Technology, 32, 1-9. Harrison, M., \& Hills, B. P. (1997b). Mathematical model of flavor release from liquids 
containing aroma-binding macromolecules. Journal of Agricultural and Food Chemistry, 45, 1883-1890.

Harrison, M., Hills, B. P., Bakker, J., \& Clothier, T. (1997). Mathematical models of flavor release from liquid emulsions. Journal of Food Science, 62, 653-664. https://doi.org/ 10.1111/j.1365-2621.1997.tb15429.x.

Hills, B. P., \& Harrison, M. (1995). Two-film theory of flavour release from solids. International Journal of Food Science and Technology, 30, 425-436.

Hollowood, T. A. (2002). Taste-aroma-matrix interactions determine flavour perception Ph.D. thesis University of Nottingham.

Hollowood, T., Linforth, R., \& Taylor, A. J. (2002). The effect of viscosity on the perception of flavour. Chemical Senses, 27, 583-591.

Hort, J. (2015). Multimodal flavour perception: Understanding sensory interactions recent advances. In A. J. Taylor, \& D. S. Mottram (Eds.). Flavour science: Proceedings of the XIV weurman flavour research symposium (pp. 263-270). Leicestershire, United Kingdom: Contexts Products Ltd.

Iannilli, E., Bult, J. H., Roudnitzky, N., Gerber, J., de Wijk, R. A., \& Hummel, T. (2014). Oral texture influences the neural processing of ortho- and retronasal odors in humans. Brain Research, 1587, 77-87. https://doi.org/10.1016/j.brainres.2014.08.063.

Jousse, F., Agterof, W., Jongen, T., Koolschijn, M., Visser, A., \& Vreeker, R. (2002). Flavor release from cooking oil during heating. Journal of Food Science, 67, 2987-2996.

Juteau-Vigier, A., Atlan, S., Déléris, I., Guichard, E., Souchon, I., \& Trelea, I. C. (2007). Ethyl hexanoate transfer modeling in carrageenan matrices for determination of diffusion and partition properties. Journal of Agricultural and Food Chemistry, 55, 3577-3584. https://doi.org/10.1021/jf0626415.

Kolb, B., \& Ettre, L. S. (2006). Static headspace-gas chromatography: Theory and practice (2nd ed.). Hoboken, N.J: Wiley.

Kora, E. P., Souchon, I., Latrille, E., Martin, N., \& Marin, M. (2004). Composition rather than viscosity modifies the aroma compound retention of flavored stirred yogurt. Journal of Agricultural and Food Chemistry, 52, 3048-3056. https://doi.org/10.1021/ jf034597o.

Kozinski, A. A., \& King, C. J. (1966). The influence of diffusivity on liquid phase mass transfer to the free interface in a stirred vessel. AIChE Journal, 12, 109-116.

Lerol, J.-C., Masson, J.-C., Renon, H., Fabries, J.-F., \& Sannier, H. (1977). Accurate measurement of activity coefficient at infinite dilution by inert gas stripping and gas chromatography. Industrial and Engineering Chemistry Process Design and Development, 16, 139-144.

Lewis, W. K., \& Whitman, W. G. (1924). Principles of gas absorption. Industrial and Engineering Chemistry, 16, 1215-1220.

Lindinger, W., Hansel, A., \& Jordan, A. (1998). On-line monitoring of volatile organic compounds at pptv levels by means of proton-transfer-reaction mass spectrometry (PTR-MS) medical applications, food control and environmental research. International Journal of Mass Spectrometry and Ion Processes, 173, 191-241. https:// doi.org/10.1016/S0168-1176(97)00281-4.

Linforth, R. S. T. (2010). Modelling flavour release. In A. J. Taylor, \& R. S. T. Linforth (Eds.). Food flavour technology (pp. 207-228). Oxford, UK: Wiley-Blackwell.

Linforth, R. S. T., \& Taylor, A. J. (1996). Apparatus and methods for the analysis of trace constituents in gases. Patent, US 5869344.

Linforth, R. S., \& Taylor, A. J. (2006). Volatile delivery under dynamic gas flow conditions. Developments in food science. Vol. 43. Developments in food science (pp. 417-420) Elsevier.

Lubbers, S., \& Butler, E. (2010). Effects of texture and temperature on the kinetic of aroma release from model dairy custards. Food Chemistry, 123, 345-350. https://doi.org/10. 1016/j.foodchem.2010.04.041.

Lubbers, S., \& Etiévant, P. (2006). Texture-flavour interactions. In A. Voilley (Ed.). Flavour in foods (pp. 327-344). Cambridge: Woodhead Publishing Ltd.

Marchello, J. M., \& Toor, H. L. (1963). Mixing model for transfer near a boundary. Industrial \& Engineering Chemistry Fundamentals, 2, 8-12. https://doi.org/10.1021/ i160005a003.

Marin, M., Baek, I., \& Taylor, A. J. (1999). Volatile release from aqueous solutions under dynamic headspace dilution conditions. Journal of Agricultural and Food Chemistry, 47, 4750-4755. https://doi.org/10.1021/jf990470g.

Marin, M., Baek, I., \& Taylor, A. J. (2000). Flavor release as a unit operation: A mass transfer approach based on a dynamic headspace dilution method. In D. D. Roberts, \& A. J. Taylor (Vol. Eds.), Flavor release: Vol. 763, (pp. 153-165). Washington, DC: American Chemical Society.

McNulty, P. (1987). Flavour release - elusive and dynamic. In J. M. V. Blanshard, \& P. Lillford (Eds.). Food structure and behavior Food science and technology (pp. 245-258). London; Orlando: Academic Press.

McNulty, P. B., \& Karel, M. (1973). Factors affecting flavour release and uptake in O/W emulsions:II. Stirred cell studies. International Journal of Food Science and Technology, 8, 319-331. https://doi.org/10.1111/j.1365-2621.1973.tb01720.x.

Morell, P., Hernando, I., \& Fiszman, S. M. (2014). Understanding the relevance of inmouth food processing. A review of in vitro techniques. Trends in Food Science \& Technology, 35, 18-31. https://doi.org/10.1016/j.tifs.2013.10.005.

Muñoz-González, C., Rodríguez-Bencomo, J. J., Moreno-Arribas, M. V., \& Pozo-Bayón, M.Á. (2011). Beyond the characterization of wine aroma compounds: Looking for analytical approaches in trying to understand aroma perception during wine consumption. Analytical and Bioanalytical Chemistry, 401, 1497-1512. https://doi.org/ 10.1007/s00216-011-5078-0.

Nahon, D. F. (1999). Psychophysical evaluation of interactive effects between sweeteners and aroma compoundsPhd. Wageningen University.

Naknean, P., \& Meenune, M. (2010). Factors affecting retention and release of flavour compounds in food carbohydrates. International Food Research Journal, 17, e34.

Normand, V., Avison, S., \& A, P. (2004). Modeling the kinetics of flavour release during drinking. Chemical Senses, 29, 235-245. https://doi.org/10.1093/chemse/bjh028.

Ollivon, M., Voilley, A., Etiévant, P., \& others (2006). Lipid-flavour interactions. Flavour in food, 133-155.

Parker, A., \& Marin, M. (2000). A gas-liquid interfacial mass-transfer cell for studying flavor release. In D. D. Roberts, \& A. J. Taylor (Vol. Eds.), Flavor release: Vol. 763, (pp. 192-200). Washington, DC: American Chemical Society.

Pearson, K. (2005). The effect of dispersion mechanisms on aroma deliveryPh.D. thesis. University of Nottingham.

Rabe, S. (2004). Dynamic flavour release from miglyol/water emulsions: Modelling and validation. Food Chemistry, 84, 117-125. https://doi.org/10.1016/S0308-8146(03) 00182-1.

Rabe, S., Krings, U., \& Berger, R. G. (2003a). Dynamic flavor release from sucrose solutions. Journal of Agricultural and Food Chemistry, 51, 5058-5066. https://doi.org/10. 1021/jf0302411.

Rabe, S., Krings, U., \& Berger, R. G. (2003b). Initial dynamic flavour release from sodium chloride solutions. European Food Research and Technology, 218, 32-39. https://doi. org/10.1007/s00217-003-0798-9.

Raffo, A. (2012). Development of new analytical methodas and application of chemometric tools in flavour researchPh.D. thesis. Università di Roma.

Richardson, J. F., Harker, J. H., Coulson, J. M., \& Richardson, J. F. (2008). Particle technology and separation processes. Number vol. 2 in coulson and richardson's chemical engineering(5th ed.). Oxford: Butterworth Heinemann.

Roberts, D. D., Elmore, J. S., Langley, K. R., \& Bakker, J. (1996). Effects of sucrose, guar gum, and carboxymethylcellulose on the release of volatile flavor compounds under dynamic conditions. Journal of Agricultural and Food Chemistry, 44, 1321-1326.

Roberts, D. D., \& Taylor, A. J. (Eds.). (2000). Flavor release volume 763 of ACS symposium series. Washington, DC: American Chemical Society.

de Roos, K. (2000). Physicochemical models of flavor release from foods. In D. D. Roberts, \& A. J. Taylor (Vol. Eds.), Flavor release: Vol. 763, (pp. 126-141). Washington, DC: American Chemical Society.

de Roos, K. B. (2003). Effect of texture and microstructure on flavour retention and release. International Dairy Journal, 13, 593-605. https://doi.org/10.1016/S09586946(03)00108-0.

de Roos, K. B. (2006a). Modelling aroma interactions in food matrices. In A. Voilley, \& P. Etiévant (Eds.). Flavour in foods (pp. 229-259). Cambridge: Woodhead Publishing Ltd.

de Roos, K. B. (2006b). Understanding and controlling the behaviour of aroma compounds in thermally processed foods. Trends in Food Science \& Technology, 17, 236-243. https://doi.org/10.1016/j.tifs.2005.11.008.

de Roos, K. B., \& Wolswinkel, K. (1994). Non-equilibrium partition model for predicting flavour release in the mouth. In H. Maarse, \& D. G. v. d. Heij (Eds.). Trends in flavour research: Proceedings of the 7th weurman flavour research symposium, noordwijkerhout, The Netherlands, 15-18 june, 1993 number 35 in developments in food science (pp. 1532). Amsterdam ; New York: Elsevier.

Rusu, M. (2006). Food matrices-Impact on odorant partition coefficients and flavour perception. Ph.D. thesis Bergische Universität Wuppertal.

van Ruth, S. M., \& Roozen, J. P. (2010). Delivery of flavours from food matrices. In A. J. Taylor, \& R. S. T. Linforth (Eds.). Food flavour technology (pp. 190-206). Oxford, UK: Wiley-Blackwell.

Saint-Eve, A. (2006). Compréhension de la libération et de la perception des compsés d'arome en condition de consommation: Cas du yaourt brassé aromatisé. Ph.D. thesis INAPG (AgroParisTech).

Samavati, V., Emam-Djomeh, Z., \& Mehdinia, A. (2014). Thermodynamic and kinetic study of volatile compounds in biopolymer based dispersions. Carbohydrate Polymers, 99, 556-562. https://doi.org/10.1016/j.carbpol.2013.08.059.

Secouard, S., Malhiac, C., Grisel, M., \& Decroix, B. (2003). Release of limonene from polysaccharide matrices: Viscosity and synergy effect. Food Chemistry, 82, 227-234. https://doi.org/10.1016/S0308-8146(02)00518-6.

Seuvre, A., Philippe, E., Rochard, S., \& Voilley, A. (2006). Retention of aroma compounds in food matrices of similar rheological behaviour and different compositions. Food Chemistry, 96, 104-114. https://doi.org/10.1016/j.foodchem.2005.02.014.

Seuvre, A.-M., Philippe, E., Rochard, S., \& Voilley, A. (2007). Kinetic study of the release of aroma compounds in different model food systems. Food Research International, 40, 480-492. https://doi.org/10.1016/j.foodres.2006.09.005.

Siefarth, C., Tyapkova, O., Beauchamp, J., Schweiggert, U., Buettner, A., \& Bader, S (2011). Influence of polyols and bulking agents on flavour release from low-viscosity solutions. Food Chemistry, 129, 1462-1468. https://doi.org/10.1016/j.foodchem. 2011.05.115.

Taylor, A. J. (2002). Release and transport of flavors in vivo: Physicochemical, physiological, and perceptual considerations. Comprehensive Reviews in Food Science and Food Safety, 1, 45-57.

Taylor, A. J., \& Linforth, R. S. T. (2010). On-line monitoring of flavour processes. In A. J. Taylor, \& R. S. T. Linforth (Eds.). Food flavour technology (pp. 266-295). Oxford, UK: Wiley-Blackwell.

Terta, M., Blekas, G., \& Paraskevopoulou, A. (2006). Retention of selected aroma compounds by polysaccharide solutions: A thermodynamic and kinetic approach. Food Hydrocolloids, 20, 863-871. https://doi.org/10.1016/j.foodhyd.2005.08.011.

Tietz, M. (2007). Starch-flavour interactionsPh.D. thesis Diss. Eidgenössische Technische Hochschule ETH Zürich Nr. 17517, 2007.

Tromelin, A., Andriot, I., \& Guichard, E. (2006). Protein-flavour interactions. In A. Voilley, \& P. Etiévant (Eds.). Flavour in foods (pp. 172-207). Cambridge: Woodhead Publishing Ltd.

Tsachaki, M., Linforth, R. S. T., \& Taylor, A. J. (2009). Aroma release from wines under dynamic conditions. Journal of Agricultural and Food Chemistry, 57, 6976-6981. https://doi.org/10.1021/jf901174y.

US EPA (2012). Estimation programs interface suite (TM) for microsoft ( $R$ ) windows.

Villamor, R. R., \& Ross, C. F. (2013). Wine matrix compounds affect perception of wine aromas. Annual Review of Food Science and Technology, 4, 1-20. https://doi.org/10. 
1146/annurev-food-030212-182707.

Voilley, A., \& Souchon, I. (2006). Flavour retention and release from the food matrix: An overview. In A. Voilley, \& P. Etiévant (Eds.). Flavour in foods (pp. 117-132). Cambridge: Woodhead Publishing Ltd.

Weel, K. G. C. (2004). Release and perception of aroma compounds during consumption. Phd Wageningen University.

Weel, K. G. C., Boelrijk, A. E. M., Burger, J. J., Verschueren, M., Gruppen, H., Voragen, A. G. J., et al. (2004). New device to simulate swallowing and in vivo aroma release in the throat from liquid and semiliquid food systems. Journal of Agricultural and Food Chemistry, 52, 6564-6571. https://doi.org/10.1021/jf049499x.

Welty, J. R. (Ed.). (2008). Fundamentals of momentum, heat, and mass transfer(5th ed.) Danver, MA: Wiley.

Weterings, M., Bodnár, I., Boom, R. M., \& Beyrer, M. (2019). The influence of agitation on aroma release. submitted.

Yang, N. (2012). Flavour reformulation and flavour stability. Ph.D. thesis University of Nottingham. 